\title{
Cartografia das pesquisas avaliativas de serviços de saúde mental no Brasil (2004-2013)
}

\section{I ${ }^{1}$ Clarissa de Rosalmeida Dantas, ${ }^{2}$ Ana Maria Galdini Raimundo Oda I}

Resumo: Este trabalho tem como objetivo mapear as pesquisas avaliativas de serviços de saúde mental, produzidas no Brasil nos últimos dez anos, a partir de levantamento em bases de dados de dissertaçôes e teses acadêmicas e de artigos científicos. Foram analisadas 68 dissertaçôes e teses e 103 artigos. A produção das dissertações e teses se concentra em instituições nos estados de São Paulo e do Rio de Janeiro, e estas se originam principalmente de programas de pós-graduação em Saúde Coletiva e em Enfermagem. Os artigos se referem a serviços localizados em número restrito de municípios das regiôes Sul e Sudeste do país, principalmente do Rio Grande do Sul e de São Paulo, havendo poucos estudos de abrangência nacional. No conjunto da produção, os serviços mais avaliados são os Centros de Atenção Psicossocial, seguidos pela Atenção Básica em Saúde. Os sujeitos de pesquisa mais frequentes são os trabalhadores de saúde mental, e em segundo lugar, os usuários. A maioria dos trabalhos usa metodologia qualitativa. Conclui-se que as pesquisas avaliativas vêm se concentrando em abordagens pouco diversificadas do processo da reforma da saúde mental, e que estas não têm abrangência suficiente para fornecer, proximamente, elementos para prover indicadores básicos nacionais de saúde mental.

> Palavras-chave: avaliação de serviços de saúde mental; pesquisa empírica - saúde mental; Centros de Atenção Psicossocial; atenção primária à saúde - saúde mental; Sistema Único de Saúde.

\author{
1 Universidade Estadual de \\ Campinas - UNICAMP - \\ Departamento de Psicologia \\ Médica e Psiquiatria. Campinas- \\ SP, Brasil. Endereço eletrônico: \\ crdantas@fcm.unicamp.br \\ ${ }^{2}$ Universidade Estadual de \\ Campinas - UNICAMP - \\ Departamento de Psicologia \\ Médica e Psiquiatria. Campinas \\ SP, Brasil. Endereço eletrônico: \\ anaoda@fcm.unicamp.br
}

Recebido em: 31/07/2014 Aprovado em: 28/10/2014 
A reforma da assistência em saúde mental está em curso há cerca de 25 anos e, com mais intensidade na última década, as mudanças na assistência vêm se ampliando e consolidando, sob as diretrizes da política nacional de saúde mental, concretizadas em mecanismos legais de regulamentação e de financiamento dos Centros de Atenção Psicossocial (CAPS) e demais equipamentos da Rede de Atenção Psicossocial (BRASIL, 1992; 2001; 2002; 2011), ainda que os aportes de recursos financeiros e humanos não correspondam ao ritmo e às necessidades de expansão da rede (WHO-AIMS, 2007).

Avaliar sistemática e amplamente os resultados advindos deste processo, no sentido de reforçar os acertos e corrigir as deficiências, bem como para subsidiar novos processos decisórios na política de saúde mental, é necessidade facilmente reconhecível. Cremos que seja consensual que isto deva ser feito através de pesquisas avaliativas em saúde ${ }^{1}$ que sigam minimamente os padrôes esperados de utilidade (fornecerem dados relevantes e necessários) e acurácia (serem capazes de informar validamente sobre o mérito das práticas e processos avaliados), além de terem exequibilidade e condução ética (HARTZ, 1999). Entretanto, são questôes em aberto o que e como avaliar, que indicadores privilegiar, que tipo de evidências produzir e como usá-las adequadamente, considerando tanto a complexidade do objeto de pesquisa (CAMPOS; ONOCKO-CAMPOS; DEL BARRIO, 2013) quanto as peculiaridades do contexto nacional (MARI; THORNICROFT, 2010).

É preciso ressaltar que, no Brasil, a formulação de uma política nacional de avaliação de políticas sociais públicas vem sendo recentemente construída (HARTZ, 1999; 2006), e tal se aplica à avaliação em saúde. É fato que as pesquisas avaliativas sobre a política de saúde mental no país são escassas e de limitado alcance (WHO-AIMS, 2007). Por razōes históricas, a contribuição acadêmica brasileira para a literatura internacional em saúde mental é reconhecidamente modesta (WHO-AIMS, 2007), embora crescente nos últimos anos (MARI et al., 2006), crescimento que seria reflexo de maior disponibilidade de financiamento para a área e, portanto, de mais pesquisadores ativos (ONOCKO-CAMPOS, 2011). Assim, este é um momento em que um balanço da produção científica recente sobre a avaliação em saúde mental, no âmbito da reforma da assistência, é especialmente pertinente. 
Neste sentido, nosso trabalho tem como objetivo produzir um mapeamento das pesquisas avaliativas em saúde mental, nos últimos dez anos (2004-2013), a partir da produção registrada em dissertações e teses e em artigos científicos. Não pretendemos aqui realizar uma meta-avaliação ou uma metassíntese, ${ }^{2}$ mas uma cartografia que mostre os caminhos seguidos pelas investigações na área.

\section{Materiais e métodos de pesquisa}

O levantamento bibliográfico se deu entre junho e julho de 2014. O limite temporal inicial para a seleção das publicações foi estabelecido em 2004, considerando a aprovação da Lei n ${ }^{\circ} 10.216$ em 2001 e, ainda, que estaria então começando a efetiva implantação das disposições da Portaria n 336/GM/MS, de 19 de fevereiro de 2002, que regulamenta as modalidades dos Centros de Atenção Psicossocial (CAPS) e estabelece as normas de funcionamento e a composição de suas equipes, colocando este serviço como regulador central na rede de atenção à saúde mental, o que não estava explicitado na legislação, até esta ocasião. ${ }^{3}$

No caso das dissertações e teses, as principais bases de dados usadas foram o Banco de Teses da Coordenação de Aperfeiçoamento de Pessoal de Nível Superior (Capes) e a Biblioteca Virtual em Saúde (BVS), tendo sido a pesquisa complementada em bibliotecas digitais de teses, tais como as da Universidade Estadual de Campinas, da Universidade de São Paulo e da Universidade do Estado do Rio de Janeiro, entre outras. Os termos de busca foram: "serviços de saúde mental", "serviços comunitários de saúde mental", "dispositivos de saúde mental", "saúde mental e hospital geral", "pesquisa avaliativa em saúde mental", "avaliação de resultados em saúde mental”.

Do resultado inicial do levantamento de teses, foram selecionadas publicações de caráter empírico, que avaliavam serviços ou redes de saúde mental e/ou intervenções e práticas na área, e excluídas aquelas que se ocupavam exclusivamente da saúde dos trabalhadores, as de cunho somente teórico, as de revisão bibliográfica e as de abordagem histórica. Foram considerados apenas trabalhos de pós-graduação em senso estrito, ou seja, de doutorado ou mestrado (acadêmico e profissional), e excluídos trabalhos de conclusão de cursos de especialização.

No levantamento de artigos publicados em periódicos científicos, os mesmos termos de busca foram adotados. Selecionamos trabalhos que apresentavam resultados empíricos de experiências de avaliação de intervenções, redes ou 
1130 serviços públicos de saúde mental, excluindo aqueles que discutiam princípios e métodos de avaliação com uma aproximação eminentemente conceitual, os que tratavam de revisão bibliográfica ou perspectiva histórica. Foram mantidos alguns estudos sobre saúde dos trabalhadores que incluíam também avaliação de aspectos dos serviços em que se inseriam. As bases de dados pesquisadas foram SciELO, SCOPUS e Google Acadêmico.

As limitações desta pesquisa devem ser assinaladas. Trata-se de uma revisão extensa, mas não exaustiva. No que se refere às dissertações e teses, o Banco de Teses da Capes, que deveria ser o principal repositório da produção acadêmica brasileira, mostrou-se incompleto, havendo várias referências de teses (identificadas na bibliografia dos artigos levantados) que não aparecem ali. Também encontramos vários trabalhos indexados na BVS que não se encontram no Banco da Capes. Assim, é possível que tenhamos deixado de identificar documentos de interesse, ainda não incluídos nestas bases de dados. Outra observação metodológica pertinente é sobre os limites impostos pelo uso dos resumos como fonte primordial de informação sobre as dissertações e teses, ponto que discutiremos adiante.

\section{Resultados do levantamento de trabalhos sobre pesquisa avaliativa em saúde mental}

\section{Sobre as dissertações e teses}

Selecionamos 68 dissertações e teses publicadas entre 2004 e 2013, segundo os critérios referidos acima, sendo 45 (66\%) dissertaçōes de mestrado, 22 teses de doutorado (32\%) e uma tese de livre-docência, distribuídas em 21 instituições de ensino superior. Destes trabalhos, extraímos dados sobre a instituição de origem, o tipo de serviço (ou intervenção, ou prática), as principais fontes de informação (ou os sujeitos de pesquisa), os métodos de pesquisa (a partir dos resumos, ou por consulta direta dos trabalhos quando tais informaçóes inexistiam ali, e o texto integral estava disponível on line) e seus principais resultados e conclusões (apenas os registrados nos resumos).

A maior parte dos trabalhos foi publicada nos últimos três anos (entre 2011 e 2013, 44 ou $65 \%$ do total - ver gráfico 1). Cerca de $90 \%$ deles se concentram em duas áreas de pós-graduação, a de Saúde Coletiva (Saúde Coletiva, Saúde Pública e Medicina Preventiva, com 38 ou 55,9\%) e a de Enfermagem (com 21 ou 
30,9\%). Quanto à origem, as instituições com maior número de trabalhos foram

a Universidade de São Paulo - USP (14 ou 20,6\%), a Universidade Estadual de Campinas - UNICAMP (12 ou 17,6\%) e a Escola Nacional de Saúde Pública Sérgio Arouca - ENSP (9 ou 13,2\%), as três reunindo mais de 50\% da produção acadêmica nacional sobre avaliação de serviços de saúde mental. Dois estados da federação foram responsáveis por dois terços da produção total, São Paulo, com $41,2 \%$ e Rio de Janeiro, com $25 \%$ (ver tabela 1, gráfico 2 e gráfico 3).

Tabela 1. Teses e dissertações sobre pesquisa avaliativa em saúde mental, segundo instituições, áreas de pós-graduação e estados de origem (2004-20013)

\begin{tabular}{|c|c|c|c|}
\hline $\begin{array}{l}\text { Número e } \\
\text { percentual de } \\
\text { trabalhos }\end{array}$ & Instituição & $\begin{array}{l}\text { Áreas de } \\
\text { Pós-Graduação }\end{array}$ & $\begin{array}{l}\text { Estado: número } \\
\text { e percentual de } \\
\text { trabalhos }\end{array}$ \\
\hline \multirow[t]{4}{*}{$14(20,6 \%)$} & Universidade de São Paulo & Enfermagem (7) & \multirow{7}{*}{$\begin{array}{l}\text { São Paulo } \\
28(41,2 \%)\end{array}$} \\
\hline & $\begin{array}{l}\text { Universidade de São Paulo/ } \\
\text { Ribeirão Preto }\end{array}$ & $\begin{array}{l}\text { Medicina } \\
\text { Preventiva (1) }\end{array}$ & \\
\hline & Universidade de São Paulo/ & Medicina - Saúde & \\
\hline & Faculdade de Saude Publica & Saúde Pública (5) & \\
\hline $12(17,6 \%)$ & $\begin{array}{l}\text { Universidade Estadual de } \\
\text { Campinas }\end{array}$ & Saúde Coletiva & \\
\hline $1(1,5 \%)$ & $\begin{array}{l}\text { Pontifícia Universidade } \\
\text { Católica de São Paulo }\end{array}$ & Psicologia & \\
\hline $1(1,5 \%)$ & Universidade Estadual Paulista & Saúde Coletiva & \\
\hline $9(13,2 \%)$ & $\begin{array}{l}\text { Escola Nacional de Saúde } \\
\text { Pública }\end{array}$ & Saúde Pública & \multirow{8}{*}{$\begin{array}{l}\text { Rio de Janeiro } \\
17(24,9 \%)\end{array}$} \\
\hline \multirow[t]{3}{*}{$3(4,4 \%)$} & \multirow{3}{*}{$\begin{array}{l}\text { Universidade Federal } \\
\text { Fluminense }\end{array}$} & Enfermagem (1) & \\
\hline & & Saúde Coletiva (1) & \\
\hline & & Psicologia (1) & \\
\hline $2(2,9 \%)$ & $\begin{array}{l}\text { Universidade do Estado do RJ / } \\
\text { Instituto de Medicina Social }\end{array}$ & Saúde Coletiva & \\
\hline $1(1,5 \%)$ & Universidade do Estado do RJ & Serviço Social & \\
\hline $1(1,5 \%)$ & $\begin{array}{l}\text { Pontifícia Universidade } \\
\text { Católica do Rio de Janeiro }\end{array}$ & Serviço Social & \\
\hline $1(1,5 \%)$ & $\begin{array}{l}\text { Universidade Federal do Rio de } \\
\text { Janeiro }\end{array}$ & Enfermagem & \\
\hline
\end{tabular}




\begin{tabular}{|c|c|c|c|}
\hline $\begin{array}{l}\text { Número e } \\
\text { percentual de } \\
\text { trabalhos }\end{array}$ & Instituição & $\begin{array}{l}\text { Áreas de } \\
\text { Pós-Graduação }\end{array}$ & $\begin{array}{l}\text { Estado: número } \\
\text { e percentual de } \\
\text { trabalhos }\end{array}$ \\
\hline $3(4,4 \%)$ & $\begin{array}{l}\text { Universidade Estadual do } \\
\text { Ceará }\end{array}$ & Saúde Coletiva & \multirow{2}{*}{$\begin{array}{l}\text { Ceará } \\
6(8,8 \%)\end{array}$} \\
\hline $3(4,4 \%)$ & Universidade Federal do Ceará & $\begin{array}{l}\text { Saúde Pública (2) } \\
\text { Psicologia (1) }\end{array}$ & \\
\hline $5(7,4 \%)$ & $\begin{array}{l}\text { Universidade Federal do Rio } \\
\text { Grande do Sul }\end{array}$ & $\begin{array}{l}\text { Enfermagem (4) } \\
\text { Educação (1) }\end{array}$ & $\begin{array}{l}\text { Rio Grande do Sul } \\
5(7,4 \%)\end{array}$ \\
\hline $3(4,4 \%)$ & $\begin{array}{l}\text { Universidade Federal de Minas } \\
\text { Gerais }\end{array}$ & Enfermagem & $\begin{array}{l}\text { Minas Gerais } \\
3(4,4 \%)\end{array}$ \\
\hline $3(4,4 \%)$ & $\begin{array}{l}\text { Universidade Federal de Santa } \\
\text { Catarina }\end{array}$ & $\begin{array}{l}\text { Enfermagem (1) } \\
\text { Saúde Coletiva (2) }\end{array}$ & $\begin{array}{l}\text { Santa Catarina } \\
3(4,4 \%)\end{array}$ \\
\hline $1(1,5 \%)$ & Universidade Federal do Paraná & Enfermagem & \\
\hline $1(1,5 \%)$ & $\begin{array}{l}\text { Universidade Estadual de } \\
\text { Maringá }\end{array}$ & Enfermagem & $\begin{array}{l}\text { Paraná } \\
2(2,9 \%)\end{array}$ \\
\hline $1(1,5 \%)$ & $\begin{array}{l}\text { Instituto de Medicina Integral } \\
\text { Professor Fernando Figueira }\end{array}$ & $\begin{array}{l}\text { Avaliação em } \\
\text { Saúde }\end{array}$ & $\begin{array}{l}\text { Pernambuco } \\
1(1,5 \%)\end{array}$ \\
\hline $1(1,5 \%)$ & $\begin{array}{l}\text { Universidade Estadual do } \\
\text { Sudoeste da Bahia }\end{array}$ & Enfermagem & $\begin{array}{l}\text { Bahia } \\
1(1,5 \%)\end{array}$ \\
\hline $1(1,5 \%)$ & $\begin{array}{l}\text { Universidade Federal do Rio } \\
\text { Grande do Norte }\end{array}$ & Enfermagem & $\begin{array}{l}\text { Rio Grande do } \\
\text { Norte } \\
1(1,5 \%)\end{array}$ \\
\hline $1(1,5 \%)$ & Universidade Federal do Pará & Psicologia & $\begin{array}{l}\text { Pará } \\
1(1,5 \%)\end{array}$ \\
\hline Total & & & $68(100 \%)$ \\
\hline
\end{tabular}


Gráfico 1. Número de teses e dissertações selecionadas, por ano de publicação

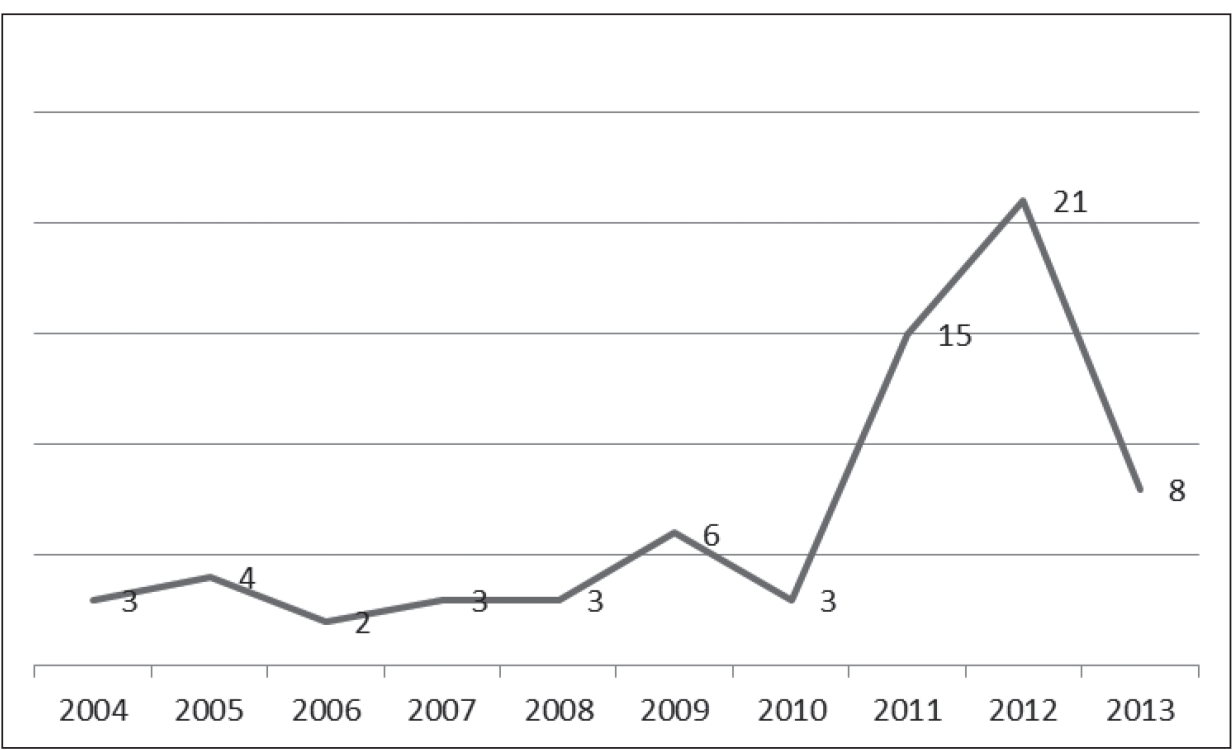

Gráfico 2. Áreas de pós-graduação (número e percentual de teses e dissertações)

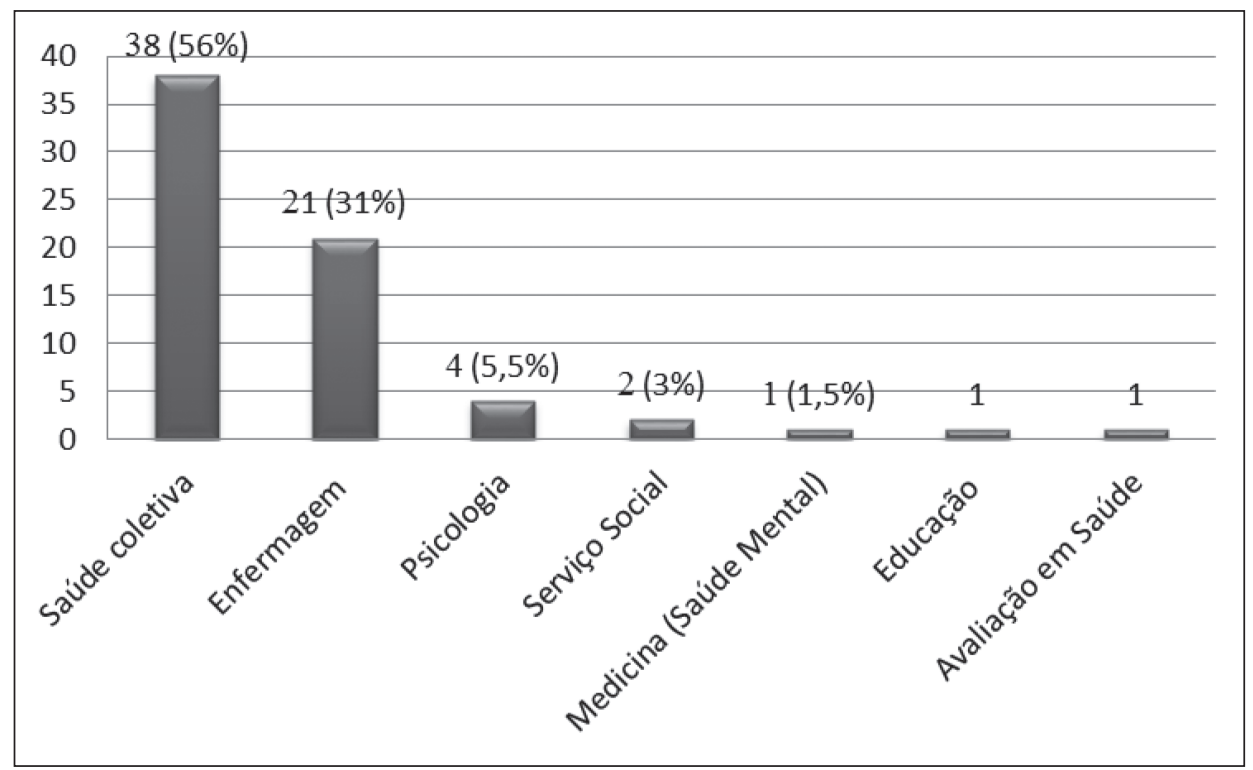




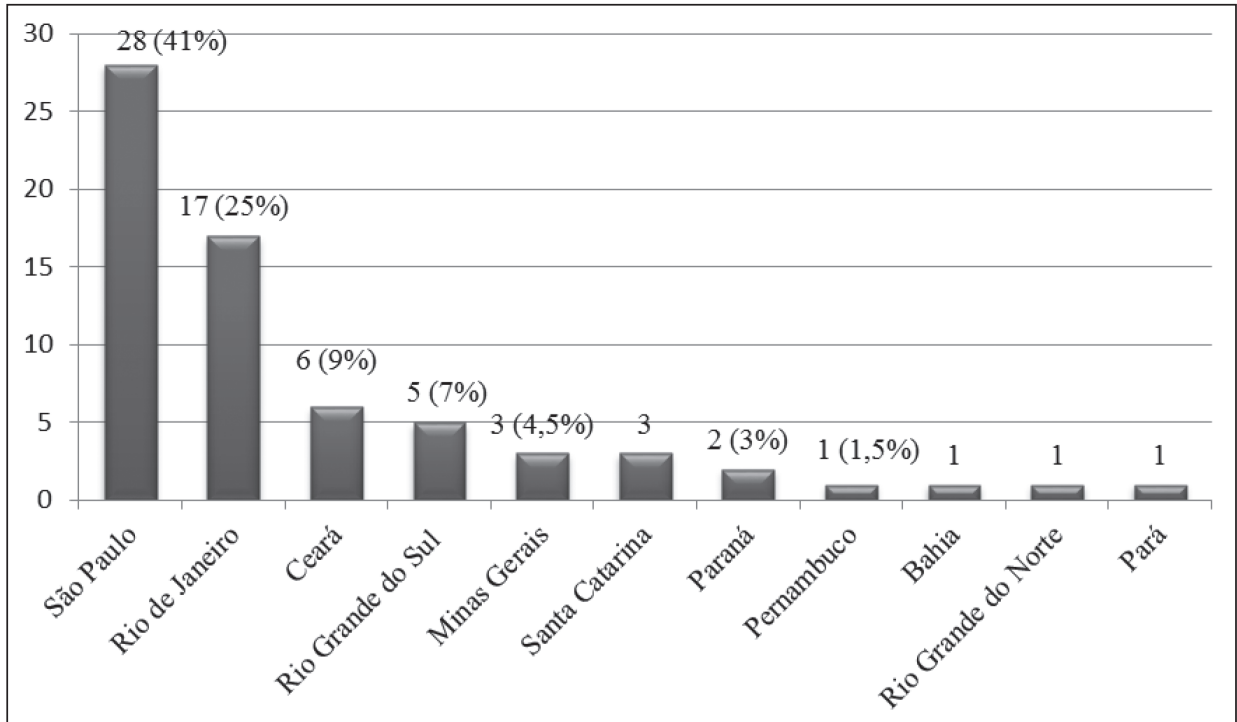

Em geral, os estudos se ocupam de um tipo de serviço de saúde mental, embora alguns incluam dois ou mais. $\mathrm{O}$ serviço mais estudado (isoladamente ou em conjunto com outros) foi o Centro de Atenção Psicossocial (CAPS), sendo objeto de estudo de 35 pesquisas (ou 51,4\% dos estudos), sendo 28 em CAPS para adultos, cinco em CAPS Infanto-Juvenis (CAPSi) e dois em CAPS para usuários de álcool e drogas (CAPSad); 28 trabalhos (41,2\%) avaliaram somente CAPS. A Atenção Básica em Saúde - ABS (atenção primária, unidade básica de saúde, centro de saúde, unidade de Saúde da Família, Estratégia de Saúde da Família) foi avaliada em 13 estudos (19,1\%); 11 estudos (16,2\%) pesquisaram serviços hospitalares (hospital geral, enfermaria psiquiátrica em hospital geral, unidade de emergência em hospital geral, hospital psiquiátrico). Apenas dois trabalhos focalizaram a implantação de sistemas de informação em saúde mental, ambos em nível municipal (OCTAVIANO, 2012; RODRIGUES, 2013), como pode ser visto no gráfico 4 . 


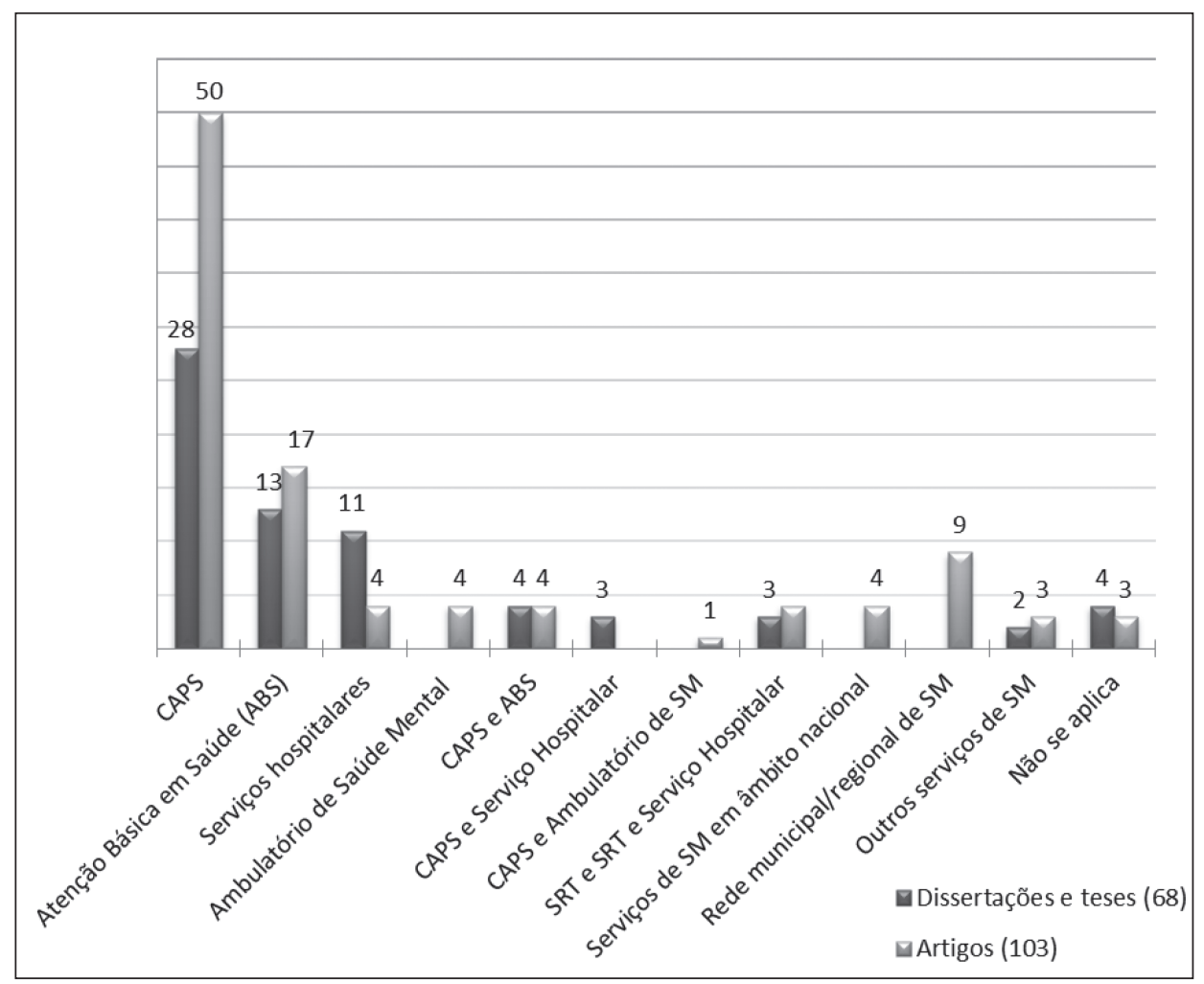

ABS - Atenção Básica à Saúde; CAPS - Centro de Atenção Psicossocial; SM - Saúde Mental; SRT - Serviço Residencial Terapêutico

As principais fontes dos dados das dissertações e teses foram os trabalhadores dos serviços em foco (e, em alguns casos, também gestores da rede de saúde mental), em 29 estudos (42,7\%) exclusivamente, e em 41 (60,3\%), considerando trabalhos com mais de um tipo de sujeitos de pesquisa; apenas os usuários diretos dos serviços foram a principal fonte de informação em 12 (17,6\%), e em conjunto com outros sujeitos (trabalhadores e/ou familiares), em 27 trabalhos (39,7\%). Dados secundários (sistemas de informação ou prontuários) foram as fontes em cinco estudos (7,4\%), e quatro trabalhos (5,9\%) usaram dados secundários e também informações provindas de trabalhadores, usuários ou especialistas em saúde mental (ver gráfico 5). 
Gráfico 5. Números de dissertações e teses e de artigos, por principal fonte de informação do estudo

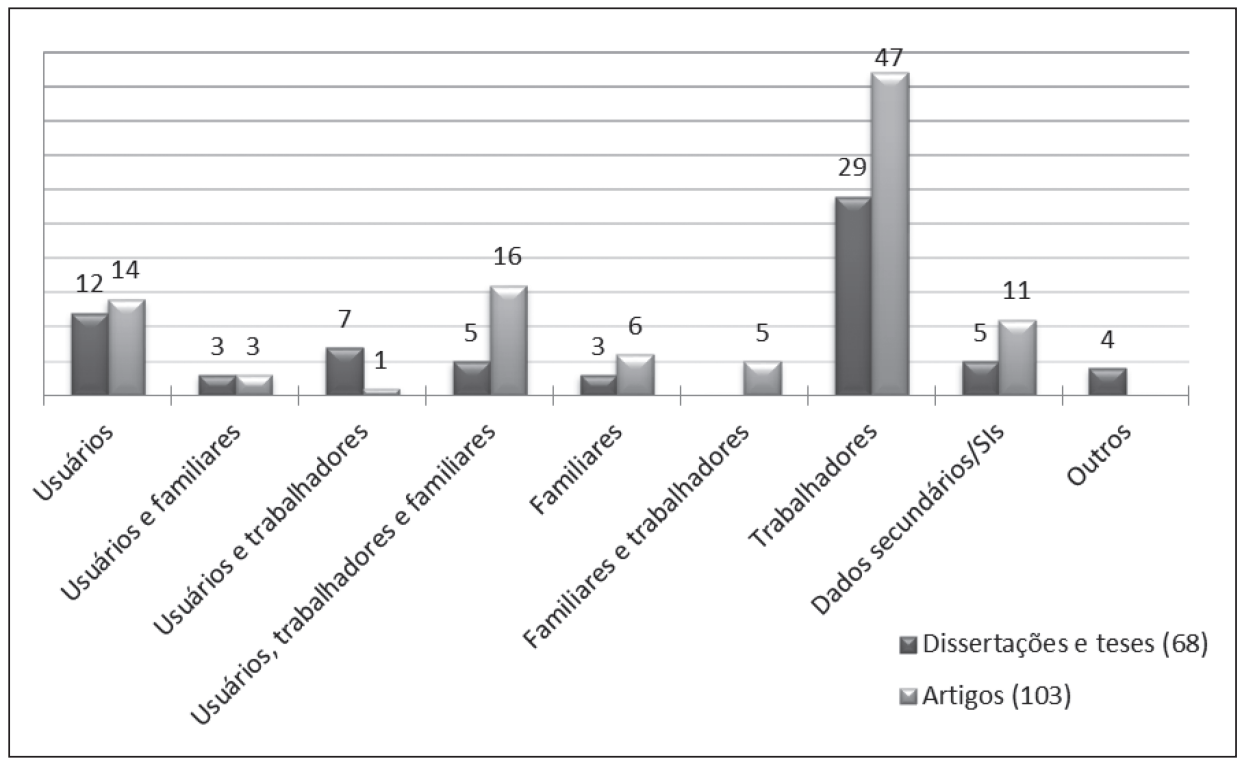

SIs - Sistemas de informação.

Considerando as informações dadas por seus autores, quanto à metodologia utilizada, do total de 68 dissertações e teses, 61 usaram metodologia qualitativa, ou seja, cerca de $90 \%$ dos trabalhos (ver lista de referências). Foram cinco os estudos quantitativos (BARROS R., 2012; FONSECA, 2011; OCTAVIANO, 2012; RODRIGUES, 2013; PONTE, 2012) e dois, os quantitativo-qualitativos (CORREA, 2011; MUNIZ, 2013). 


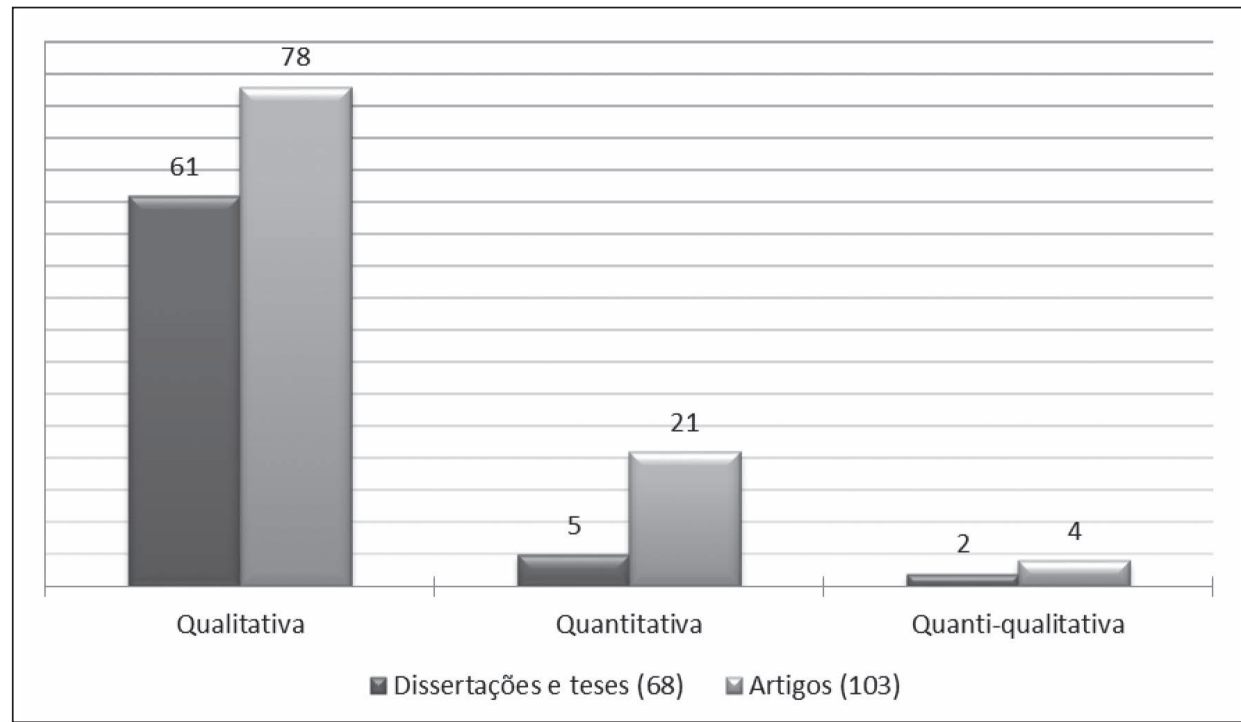

Tendo sido os resumos das teses a principal fonte de informaçôes para o nosso levantamento, cabe uma observação importante sobre a qualidade destes: muitos são incompletos e não fornecem dados relevantes sobre a pesquisa, tais como os sujeitos em foco, os serviços ou práticas avaliados e os resultados obtidos, e cerca de um quarto deles não indicam ali as conclusões do estudo. Muitas vezes, pareceu-nos que as conclusões registradas nos resumos são como prescrições sobre a rede de saúde mental ideal, ou que incorrem em generalizações que não seriam autorizadas pelo caráter declarado das pesquisas. E, observamos adicionalmente, ainda que a qualidade do resumo possa não refletir a qualidade do trabalho de pesquisa, chamou-nos a atenção que este instrumento tão relevante na divulgação das teses não venha sendo mais bem cuidado. 
Selecionamos 103 artigos, publicados entre 2004 e 2013, cuja distribuição por ano de publicação se encontra representada no gráfico 7 . Três periódicos concentram cerca de metade dessa produção: Ciência \& Saúde Coletiva (27 artigos ou 26,2\%), Cadernos de Saúde Pública (14 artigos, 13,6\%) e Physis: Revista de Saúde Coletiva (12 ou $11,7 \%)$.

\section{Gráfico 7. Número de artigos selecionados por ano de publicação}

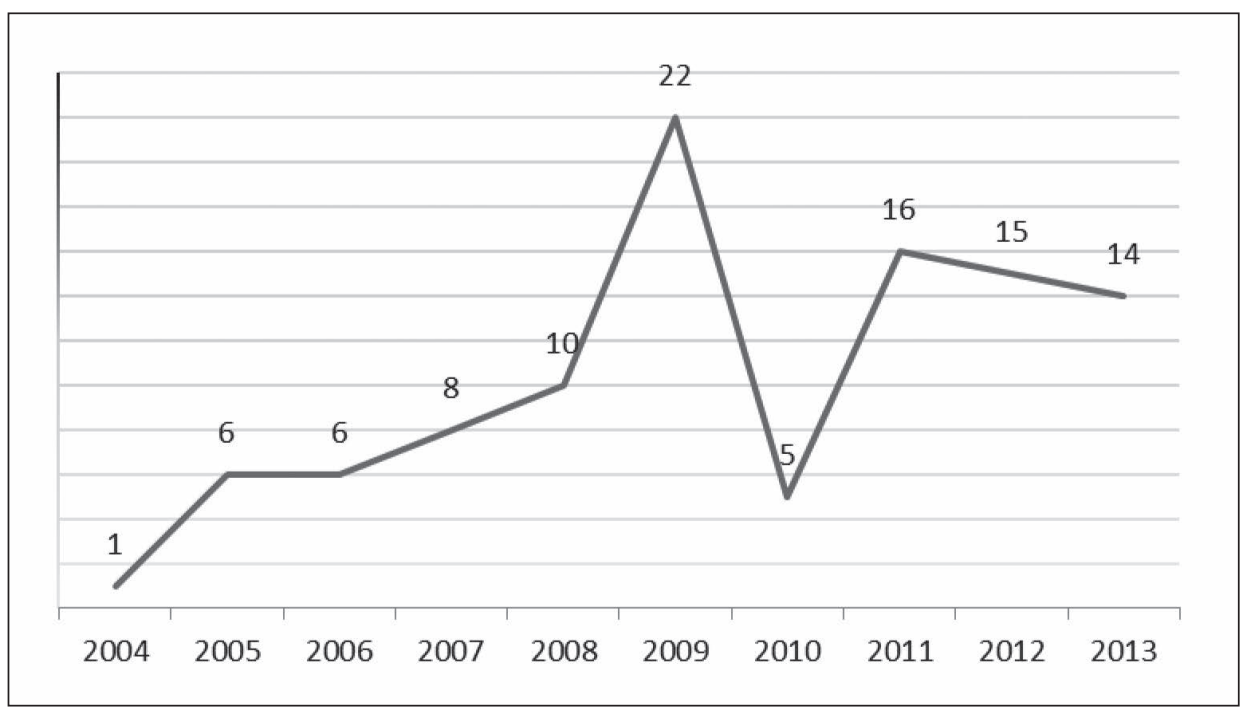

Apenas 11 das publicações de que vamos tratar a seguir têm como primeiro autor pesquisadores que também são autores de dissertações ou teses já apresentadas aqui, representando sínteses ou recortes específicos de alguns dos trabalhos já descritos. Assim, os dois conjuntos de publicações, o de artigos e o de dissertaçōes e teses, apresentam informaçōes essencialmente complementares sobre a pesquisa em avaliação de serviços públicos brasileiros de saúde mental na última década, e o fato de compartilharem muitas de suas características, como veremos adiante, não se deve meramente à redundância.

As considerações feitas a respeito da qualidade dos resumos das dissertaçóes e teses poderiam aplicar-se, em termos gerais, aos resumos dos artigos. Em vista disso, os artigos foram lidos integralmente. 
Tal como em dissertações e teses, na maior parte dos trabalhos divulgados nos periódicos científicos, um único tipo de serviço de saúde mental foi objeto de estudo e, novamente, o CAPS foi o campo de pesquisa mais frequente, sendo estudado (isoladamente ou em conjunto com outro tipo de serviço) em 54 trabalhos $(52,4 \%)$. CAPS para adultos foram campo de pesquisa em 52 artigos, CAPSi, em seis (CALGARO; SOUZA, 2009; CARVALHO; SILVA; RODRIGUES, 2009; COUTO; DUARTE; DELGADO, 2008; DELFINI; REIS, 2008; HOFFMANN; SANTOS; MOTA, 2008; LIMA et al., 2012), e CAPSad, em cinco (CALGARO; SOUZA, 2009; CARVALHO; SILVA; RODRIGUES, 2009; ALVES; DOURADO; CÔRTES, 2013; JORGE et al., 2012; LIMA et al., 2012).

Nove pesquisas enfocaram não apenas um ou dois serviços, mas redes municipais ou regionais de atenção à saúde mental (CONSOLI; HIRDES; COSTA, 2009; DELFINI; REIS, 2008; FIGUEIREDO; CAMPOS, 2009; LUZIO; LABBATE, 2009; PINTO et al., 2012; QUINDERÉ et al., 2013; TÓFOLI; FORTES, 2007; SOUSA et al., 2011; ZAMBENEDETTI; PERRONI, 2008). Nesses trabalhos, o objeto de avaliação foi, sobretudo, a articulação da rede, e o apoio matricial foi a estratégia (ou ferramenta) de articulação mais estudada. Vale notar que um relevante trabalho realizado pelo Conselho Regional de Medicina do Estado de São Paulo (CREMESP), nos anos de 2008 e 2009, com avaliação de 85 CAPS de todo o estado (representando, na ocasião, $40 \%$ da rede instalada) tendo como parâmetros as determinações da Portaria n. 336/GM/MS-2002, não foi incluído neste levantamento por ter sido publicado em forma de livro (CREMESP, 2010).

Apenas quatro artigos relatam pesquisas avaliativas com abrangência nacional (COUTO; DUARTE; DELGADO, 2008; HOFFMANN; SANTOS; MOTA, 2008; KILSZTAJN et al., 2008; MATEUS et al., 2008). A distribuição dos trabalhos por tipo de serviço avaliado está representada no gráfico 4 .

Buscamos identificar os estados e municípios em que se localizavam os serviços avaliados, sempre que pertinente. Os estados mais mencionados nos artigos são os das regiōes Sul e Sudeste no país, particularmente Rio Grande do Sul e São Paulo. Note-se ainda que, mesmo em cada um desses estados, as publicações referem-se a um número restrito de municípios. Em São Paulo, por exemplo, 
a capital e Campinas concentram juntas mais de metade das menções. Não há qualquer referência à avaliação específica de serviços localizados nos estados das regiōes Norte e Centro-Oeste do Brasil. O gráfico 8 traz o número de referências a municípios por estado.

\section{Gráfico 8. Referências por localização dos serviços nos estados brasileiros}

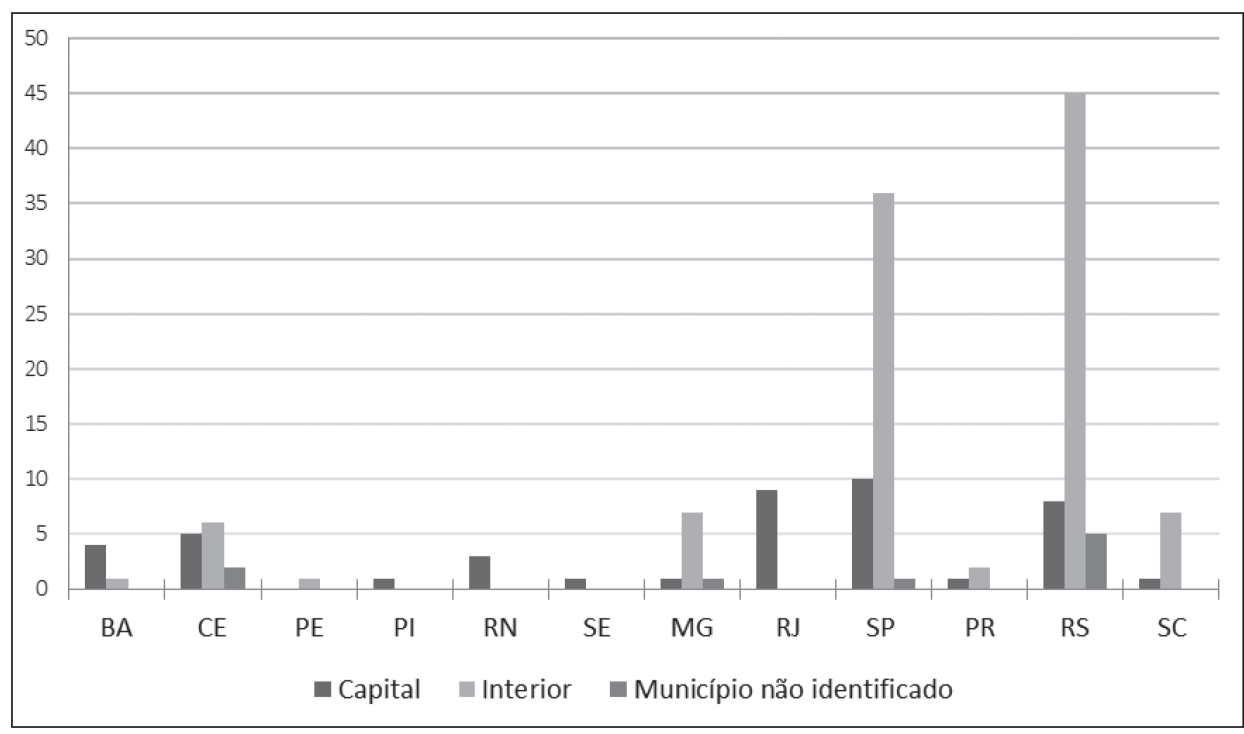

Dados secundários foram a principal fonte de informação em 11 estudos, dos quais cinco (COUTO; DUARTE; DELGADO, 2008; HOFFMANN; SANTOS; MOTA, 2008; KILSZTAJN et al., 2008; MATEUS et al. 2008; PEREIRA et al., 2012) utilizaram sistemas de informação sob gerenciamento do Sistema de Informática do SUS (DATASUS): o Cadastro Nacional de Estabelecimentos de Saúde (CNES), o Sistema de Informações Hospitalares do SUS (SIH/SUS), e o Sistema de Informaçōes Ambulatoriais do SUS (SIA/ SUS). Assim como em dissertações e teses, nos artigos a principal fonte de informação das pesquisas (ou sujeitos, coatores, ou coprodutores delas) foram os trabalhadores de saúde mental (incluindo gestores, em alguns estudos), que estiveram presentes como único grupo de interesse em 47 estudos (45,6\%) e, se considerarmos também trabalhos que abordaram mais de um grupo de interesse, participaram de 69 estudos (67,0\%). Os usuários diretos dos serviços participaram (como grupo único ou em conjunto com outros informantes) 
de cerca de um terço das pesquisas (34 ou 33,1\%). Dezesseis estudos (15,5\%)

envolveram concomitantemente trabalhadores de saúde mental, usuários diretos dos serviços, e familiares de usuários. (A distribuição dos artigos por principal fonte de informação encontra-se representada no gráfico 5).

Também entre os artigos há larga predominância de trabalhos que adotam metodologia qualitativa (78, ou $75,7 \%$ dos artigos). Resultam de estudos quantitativos, 21 artigos (ver lista de artigos selecionados), e quatro recorreram a métodos quantitativo-qualitativos (KANTORSKI et al., 2009; NASCIMENTO; GALVANESE, 2009; TANAKA; LAURIDSEN-RIBEIRO, 2006; TANAKA; RIBEIRO; 2009). (Ver gráfico 6).

\section{Resultados das pesquisas avaliativas publicadas em artigos}

Quantos aos resultados das pesquisas avaliativas realizadas no Brasil, no decorrer da última década, limitamo-nos aos trabalhos publicados em periódicos, dos quais nos foi possível uma leitura completa.

Sintetizar tais resultados é árdua tarefa. Com a maioria das pesquisas sendo orientadas por abordagens qualitativas, ganham proeminência aspectos singulares e contextuais dos dispositivos avaliados, tornando um desafio a articulação de resultados produzidos em diferentes situações. Uma constatação é ilustrativa dessa dificuldade: grosso modo, nas discussōes que os autores fazem dos resultados apresentados, o diálogo se estabelece muito mais com referências teóricas e documentais do que com outros trabalhos empíricos de avaliação de serviços de saúde mental.

$\mathrm{Na}$ tentativa de apresentar um panorama (sempre incompleto e provisório), buscamos organizar os resultados apresentados pelos artigos levantados em cinco categorias, em parte, sugeridas pelos próprios títulos dos trabalhos: "dados nacionais"; "práticas"; "indicadores avaliativos", "perspectiva do trabalhador"; "perspectiva de usuários e familiares".

\section{Dados nacionais}

Três estudos quantitativos publicados em 2008 trazem dados de abrangência nacional (MATEUS et al., 2008; KILSZTAJN et al., 2008; HOFFMAN et al., 2008). Em um deles (MATEUS et al., 2008) as seçōes "Serviços de Saúde Mental" e "Recursos Humanos" do Instrumento de Avaliação para Serviços 
de Saúde Mental da Organização Mundial da Saúde (WHO-AIMS) foram aplicados ao sistema público de saúde mental brasileiro a partir de dados de 2005, gerenciados pelo DATASUS: SIH-SUS, SAI-SUS e CNES. Naquele ano, o número de psiquiatras trabalhando ainda era considerado longe do ideal segundo os padróes propostos pela OSM. Havia, em especial, grande carência de psiquiatras de crianças. Psiquiatras e outros trabalhadores de saúde mental especializados concentravam-se nas capitais e em todas as regiōes havia insuficiência de profissionais de enfermagem psiquiátrica. O número de CAPS no país quase triplicou entre o fim de 2001 e junho de 2006 (passando de 295 a 848); entretanto, esses serviços substitutivos estavam concentrados nas regiōes Sul e Sudeste do Brasil e, mesmo nessas regiōes mais ricas, o número de CAPSi ainda foi considerado bem abaixo das necessidades da população. Um grupo estava particularmente desassistido pelo sistema: o de pessoas com deficiência intelectual (MATEUS et al., 2008; HOFFMAN et al., 2008).

O número de leitos em hospitais psiquiátricos vinha em declínio e aumentava o número leitos psiquiátricos em hospitais gerais. A diminuição da ocupação de leitos psiquiátricos pelo SUS entre 1994 e 2004 também foi constatada em outro estudo (KILSZTAJN et al., 2008). Apesar dessa redução, o valor pago pelo SUS para internações de pacientes com transtornos mentais atingiu $\mathrm{R} \$ 487$ milhōes em 2004, sendo hospitais privados responsáveis por 78,8\% do total de leitos psiquiátricos ocupados pelo Sistema Único de Saúde.

\section{Práticas}

$\mathrm{Na}$ maior parte dos estudos realizados em CAPS, a avaliação voltou-se sobre o que é, com frequência, denominado o "cotidiano do serviço" (ver, por exemplo: GUIMARÃES; JORGE; ASSIS, 2011; JORGE et al., 2011; NUNES et al., 2008; PINHO et al., 2011; SCHMIDT; FIGUEIREDO; 2009; TAVARES; SOBRAL, 2005) e não sobre intervençooes específicas. As práticas, sejam elas organizacionais ou clínicas, que compõem esses cotidianos são descritas muito mais em termos éticos do que técnicos, apontando valores e princípios que atravessam a atividade de trabalho mais que descrevendo como é realizada (por exemplo: ATHAYDE; HENNINGTON, 2012; JORGE et al., 2011; LIMA et al., 2012; SCHMIDT; FIGUEIREDO; 2009).

Há menção a "diversas modalidades terapêuticas (grupais, individuais, domiciliares e comunitárias)" (SURJUS; CAMPOS, 2011, p. 128; LIMA et al., 
2012; MIELKE et al., 2012) voltadas essencialmente para os usuários diretos, mas algumas também para familiares de usuários (BIELEMANN et al., 2009; MIELKE et al., 2012; CAMPOS et al., 2009). Nas “oficinas terapêuticas" são desenvolvidas, em grupo, atividades que envolvem: dança, música, teatro, rádio, marcenaria, culinária, costura e outros trabalhos manuais e recursos expressivos (GALVANESE; NASCIMENTO; D'OLIVEIRA, 2013; MIELKE et al., 2009a; MIELKE et al., 2009b; TAVARES; SOBRAL, 2005). Também são mencionadas assembleias com trabalhadores, usuários e, em alguns serviços, familiares (por exemplo: PANDE; AMARANTE, 2011; SILVA; LANCMAN; ALONSO, 2009; SURJUS; CAMPOS, 2011) e visitas domiciliares (MIELKE et al., 2009a; MIELKE et al., 2009b; PINHO; HERNÁNDEZ; KANTORSKI, 2010).

O relacionamento entre usuários diretos e trabalhadores é muito valorizado em praticamente todos os estudos. "A relação é terapêutica, e não a atividade (LIMA et al., 2012, p. 425)”. Defende-se que o trabalho clínico seja centrado no que alguns autores chamam de "uma 'clínica do encontro'- pautada no diálogo, na escuta interessada, na produção de intersubjetividades, na troca, na partilha" (NUNES et al., 2008, p.195) - enquanto por outros é referido como "tecnologias leves" (AMARANTE et al., 2011; ARAÚJO; TANAKA, 2012; BARROS; JORGE; VASCONCELOS, 2013; JORGE et al., 2012; PINHO et al., 2011; SOUSA; JORGE; VASCONCELOS, 2011; LIMA et al., 2012) constituídas por "momentos de possíveis cumplicidades, nos quais pode haver a produção de uma responsabilização em torno do problema que vai ser enfrentado, ou mesmo de momentos de confiabilidade e esperança, nos quais se produzem relações de vínculo e aceitação" (MERHY, 1999).

Uma forma de organização de trabalho ganha destaque em vários estudos: a constituição de "equipes de referência" ou de um "técnico/profissional de referência" (por exemplo: MIELKE et al., 2012; MIRANDA; ONOCKOCAMPOS, 2010; SILVA; 2005; SILVA, 2009; SURJUS; CAMPOS, 2011). Na descrição de Silva (2005), a equipe, e particularmente o técnico/profissional, de referência responsabiliza-se pela gestão dos cuidados necessários à saúde mental de um grupo de usuários do serviço, tomando para si o encargo de acompanhar e avaliar o conjunto de ações terapêuticas que deverão potencializar seu processo de reabilitação psicossocial, garantindo a continuidade no atendimento e estabelecendo com o usuário um vínculo de confiança. Também caberia à equipe de referência 
1144 mediar as relações dos usuários com seus familiares e com a comunidade no sentido de aumentar sua "contratualidade" (SILVA, 2009, p. 154). "Transitar entre a construção coletiva do tratamento e a relação íntima e espontânea com os pacientes, no meio social destes, constitui a delicada tarefa dos profissionais de referência" (MIRANDA; ONOCKO-CAMPOS, 2010, p. 1.160).

Quanto à inserção de cuidados de saúde mental na Atenção Básica em Saúde, o grau de integração de práticas variou muito entre os serviços estudados, havendo desde experiências de maior apropriação de cuidados em saúde mental (com recurso às chamadas "tecnologias leves") pelas equipes de ABS e estabelecimento de parcerias mais bem estruturadas com equipes de saúde mental - descritas como: discussão conjunta de casos e corresponsabilização pelo tratamento dos usuários (CAMPOS et al., 2011a), até a constatação de pobre inserção do cuidado em saúde mental em alguns dos serviços de ABS avaliados, com práticas centradas em triagem e encaminhamento de casos, por vezes automáticos (RIBEIRO et al., 2010; ARAÚJO; TANAKA, 2012; CAMPOS et al., 2011a; CONSOLI; HIRDES; COSTA, 2009; LUZIO; L'ABBATE, 2009; RIBEIRO et al., 2009). A implementação de ações voltadas para a saúde mental foi percebida por pesquisadores como particularmente insuficiente, ou insatisfatória, no que diz respeito aos cuidados voltados para crianças e adolescentes (CAVALCANTE; JORGE, SANTOS, 2012; DELFINI; REIS, 2012; TANAKA; LAURIDSENRIBEIRO, 2006; TANAKA; RIBEIRO, 2009).

Uma prática foi frequentemente o foco da avaliação nos estudos que envolveram a ABS: o apoio matricial (CAMPOS et al., 2011a; CAVALCANTE; JORGE; SANTOS, 2012; FIGUEIREDO; CAMPOS, 2009; MIELKE; OLSCHOWSKY, 2010; PINTO et al., 2012; QUINDERÉ et al., 2013; SOUSA et al., 2011; TÓFOLI; FORTES, 2007). Segundo documento da Coordenação Geral da Saúde Mental (CGSM) - DAPE/SAS - Ministério da Saúde (BRASIL, 2007), esta estratégia consiste em ações de supervisão, atendimento compartilhado e capacitação em serviço, realizadas por uma equipe de saúde mental para equipes ou profissionais de ABS. Propõe-se que ocorra através de discussões compartilhadas de casos, e ações conjuntas como: atendimento, intervenções no território, e planejamento de ações ofertadas, visando ao aumento da capacidade resolutiva da equipe de ABS, a ampliação e qualificação das ofertas no território e capilarização de saberes técnicos (CAMPOS et al., 2011a). 
Alguns artigos relatam experiências bem-sucedidas de apoio matricial, nas quais a implementação da estratégia aproximou-se da proposta original e, na visão dos atores envolvidos, teve efeitos na direção desejada (CAMPOS et al., 2011a; FIGUEIREDO; CAMPOS, 2009; QUINDERÉ et al., 2013; TÓFOLI; FORTES, 2007), mostrando-se "potente para definir fluxos, qualificar as equipes e promover uma assistência conjunta e compartilhada” (CAMPOS et al., 2011a, p. 4.643). Mas também há menção a uma grande diversidade de formas de realização de apoio matricial, algumas delas bastante descaracterizadas em relação à proposta da estratégia, com encontros acontecendo de maneira precária e com pouco envolvimento das equipes, limitando-se à discussão de casos ou a definir encaminhamentos (CAMPOS et al., 2011a; CAVALCANTE; JORGE; SANTOS, 2012).

\section{Indicadores avaliativos}

Nos estudos de metodologia quantitativa, os indicadores de avaliação tendem a ser bem definidos. Observe-se que a adequação de tais parâmetros quantitativos à complexidade do objeto da avaliação é, com frequência, questionada por críticos que lhes atribuem um caráter apriorístico, verticalizado e extrínseco às realidades sobre as quais se volta (WETZEL et. al., 2011; WETZEL; KANTORSKI, 2004; FURTADO et al., 2013, CAMPOS; ONOCKOCAMPOS; DEL BARRIO, 2013).

Nas pesquisas qualitativas, os parâmetros de julgamento utilizados são menos explícitos. Podemos dizer, em termos gerais, que tais estudos adotam, com diferentes graus de explicitação, os princípios da chamada Reforma Psiquiátrica brasileira como parâmetros de avaliação. Entretanto, não descrevem de que forma tais princípios são transpostos em indicadores (por exemplo: ANTUNES; QUEIROZ, 2007; NUNES; JUCÁ; VALENTIM, 2007; OLSCHOWSKY et al., 2009; PINHO et al., 2010; QUEIROZ; DELAMUTA, 2011). A dificuldade em realizar essa operacionalização é reiteradamente apontada nos artigos - em um dos trabalhos os autores chegam a ser referir ao que consideram "o caráter intangível das atividades do CAPS” (SILVA; LACMAN; ALONSO, 2009). O julgamento sobre o grau de adequação dos serviços, práticas e intervenções aos princípios da Reforma baseia-se, frequentemente, na perspectiva de atores envolvidos no cotidiano dos serviços (por exemplo: ANTUNES; QUEIROZ, 2007; BIELEMANN et al., 2009; SURJUS; CAMPOS, 2011). 
Em boa parte dos artigos levantados, os autores declaram a natureza não apenas qualitativa, mas também participativa das pesquisas que relatam (como exemplos: CAMPOS; GAMA; FERRER et al., 2011; FIORATI; SAEKI, 2011; ONOCKO-CAMPOS et al., 2012; PASSOS et al., 2013; SCHNEIDER et al., 2013; SURJUS; CAMPOS, 2011; WETZEL et al., 2011). Nesses estudos, dá-se maior ênfase ao processo de avaliação, com a construção coletiva de indicadores avaliativos mediante interação e negociação entre grupos de interesse, e menor ênfase é dada aos resultados da avaliação. Alguns dos trabalhos (CAMPOS et al., 2009; FURTADO et al., 2013; MIRANDA; ONOCKO-CAMPOS, 2011; PASSOS et al., 2013) descrevem justamente a elaboração participativa de indicadores para a avaliação em saúde mental e sugerem, particularmente para avaliação dos CAPS, os seguintes parâmetros (essencialmente voltados para os processos de trabalho):

a) Para CAPS que possuem "leito-noite" (caso dos CAPS III): "verificação periódica da taxa de ocupação e permanência nos leitos, bem como percentagens referentes a: atendimentos a pacientes em crise sem ocupação de leitos, usuários encaminhados para uso de leitos em outros serviços, e usuários com diagnósticos de comorbidade que demandam acompanhamento intensivo" (CAMPOS et al., 2009, p. 18).

b) Para a avaliação do projeto terapêutico individual (PTI) e equipes/ profissionais de referência: "verificação periódica da percentagem de usuários que utilizam outros recursos da rede, tiveram seu PTI discutido no último ano, foram atendidos por outros profissionais além do seu técnico de referência”. (CAMPOS et al., 2009, p. 19). Adicionalmente, quantas das discussões de PTI incluíram o usuário e sua família; e se a equipe de referência discute pelo menos dois casos por semana (MIRANDA; ONOCKO-CAMPOS, 2011).

c) Para a avaliação das práticas grupais: "planejamento de recursos e competências necessárias para o desenvolvimento das práticas grupais, a existência de grupos para familiares e critérios de participação, bem como a inclusão de usuários na construção e avaliação dos grupos oferecidos; mapeamento dos grupos existentes dentro e fora do território do CAPS; e o estabelecimento de parcerias com outros serviços da rede para a realização grupos" (CAMPOS et al., 2009, p. 19). 
d) Para a gestão dos CAPS: "participação regular dos gestores dos CAPS nos fóruns intersetoriais, nas intervenções do CAPS no território, nas atividades que incluem familiares e a existência de conselho gestor e outros arranjos participativos da gestão, como as assembleias" (CAMPOS et al., 2009, p. 19). E ainda: "participação dos gestores nas decisões clínicas e na construção dos PTI, sobre a existência de supervisão clínico-institucional, de formação continuada, de atenção interdisciplinar na atenção à crise durante a noite e nos fins de semana e de participação da equipe noturna na discussão dos PTI” (CAMPOS et al., 2009, p. 19). [Os dois últimos aplicam-se somente aos CAPS III]. Para a articulação com a rede de ABS: "número de serviços que compartilham projetos com o CAPS" (CAMPOS et al., 2009, p. 20).

e) Educação profissional: "percentagem de trabalhadores envolvidos com algum tipo de formação profissional, bem como daqueles que recebem subsídios da instituição para tal" (CAMPOS et al., 2009, p. 20).

\section{Perspectiva do trabalhador}

$\mathrm{Na}$ maior parte dos estudos, os trabalhadores ouvidos foram aqueles ligados aos CAPS, por isso nos limitaremos a tentar reconstruir, a partir dos resultados apresentados nos artigos, pontos de vista de profissionais sobre questões relacionadas a esse tipo de serviço. Predominam, entre os trabalhadores ligados aos CAPS, aqueles que declaram seu compromisso com os princípios da Reforma Psiquiátrica (ANTUNES; QUEIROZ, 2007; ATHAYDE; HENNINGTON, 2012; CAMPOS et al., 2009; MIELKE et al., 2009b; NARDI; RAMMINGER, 2007; NUNES et al., 2008). O projeto da reforma é geralmente concebido pelos entrevistados em termos de: "rompimento paradigmático com a forma de tratamento da loucura, a reversão do modelo hospitalocêntrico, a criação de novos serviços, a nova legislação, a humanização no atendimento e, principalmente, a cidadania e inclusão social dos portadores de sofrimento psíquico" (NARDI; RAMMINGER, 2007, p. 275). O envolvimento "político e afetivo" (NARDI; RAMMINGER, 2007, p. 275) com tal projeto faz com que o trabalho no CAPS adquira, por vezes, o sentido de um ativismo ou militância (ATHAYDE; HENNINGTON, 2012; NARDI; RAMMINGER, 2007). Entretanto, houve serviços nos quais prevaleceram concepções mais vagas sobre o que representa 
1148 a reforma e o desconhecimento sobre a Política Nacional de Saúde Mental (ALVES; DOURADO; CÔRTES, 2013).

$\mathrm{O}$ trabalho no CAPS é frequentemente considerado exigente e desgastante por boa parte dos profissionais que participaram dos estudos, mas também gratificante e satisfatório (ALVES; DOURADO; CÔRTES, 2013; ATHAYDE; HENNINGTON, 2012; CAMPOS et al., 2009; GUIMARÃES et al., 2011), sendo as relações estabelecidas com os usuários a principal fonte de gratificação e satisfação apontadas (ALVES; DOURADO; CÔRTES, 2013; ATHAYDE; HENNINGTON, 2012; CAMPOS et al., 2009; GUIMARÃES et al., 2011; MIELKE et al., 2009a). Entre os motivos de insatisfação, predominam queixas quanto à carência de recursos humanos e materiais nos serviços (ALVES; DOURADO; CÔRTES, 2013; ATHAYDE; HENNINGTON, 2012; GUIMARÂES et al., 2011; MIELKE et al., 2009a), tais como: falta de pessoal, de instalações adequadas; de materiais para realização de oficinas, de veículo para visitas domiciliares, de alimentação para as refeições de pacientes, (ATHAYDE; HENNINGTON, 2012; MIELKE et al., 2009b), e em alguns casos, de suprimento regular de medicações básicas (ATHAYDE; HENNINGTON, 2012).

Nos serviços estudados, nos quais a organização do trabalho em equipes e profissionais de referência é adotada, esse arranjo é valorizado (CAMPOS et al., 2009; MIRANDA; ONOCKO-CAMPOS, 2010). Os trabalhadores tendem a considerar as equipes de referência como espaços de compartilhamento dos casos e de trocas de saberes, embora reconheçam que, nem sempre, isso de fato ocorre (MIRANDA; ONOCKO-CAMPOS, 2010). A centralização do seguimento dos cuidados no técnico/profissional de referência é vista como importante e favorecedora do estabelecimento de um vínculo de confiança com o usuário, mas por outro lado, aponta-se, pode dificultar a divisão de responsabilidades (CAMPOS et al., 2009; PINHO et al., 2011) e sobrecarregar o técnico/ profissional de referência, fazendo com que seja "responsabilizado pela vida do paciente e não apenas pelo seu tratamento" (narrativa de trabalhador em MIRANDA; ONOCKO-CAMPOS, 2010, p. 1.157).

Quanto às reuniōes gerais de equipe, as avaliações foram variáveis, sendo percebidas diferentemente nos diversos serviços e entre trabalhadores com diferentes funçōes dentro dos CAPS. Em alguns contextos, a reunião de equipe foi considerada um "exercício de trabalho colegiado" (ANTUNES; QUEIROZ, 
2007, p. 211). Em outros, as reuniōes de equipe eram percebidas como espaços onde as ações/atividades do trabalhador são expostas ao julgamento dos pares e gestores imediatos, gerando alívio e satisfação quando aprovadas e consideradas em "conformidade ética e técnica aos preceitos da Reforma Psiquiátrica e ao chamado 'projeto clínico-político' da Unidade” (ATHAYDE; HENNINGTON, 2012, p. 994); ou "ruídos cuja repercussão se estendia para fora da reunião e chegava à sala da equipe, como se fossem problemas apenas pessoais", quando "a discussão dos problemas de algum usuário e de seu cuidado era [percebida como] uma maneira de questionar e criticar indiretamente a conduta de algum membro da equipe" (LUZIO; L’ABBATE, 2009, p. 110).

Em um estudo que se voltou especificamente para as percepçôes de auxiliares e técnicos de enfermagem acerca do trabalho no CAPS, foram apontados conflitos relacionados à hierarquia institucional, manifestos, não apenas, mas também nas reuniões de equipe. Esses trabalhadores sentiam-se desvalorizados pelos colegas de equipe e acreditavam que sua competência e experiência não eram reconhecidas, o que os desestimulava a compartilhar seus saberes, sendo considerado o principal desencadeante de sofrimento no trabalho (CAMPOS; BACARI, 2011; CAMPOS et al., 2009).

Em relação às oficinas e atividades grupais oferecidas pelos CAPS, os trabalhadores majoritariamente as valorizam, mas também reconhecem suas limitações. "Muitas delas, conforme alguns depoimentos, ainda são oferecidas mais como uma alternativa de entretenimento e ocupação do que como uma estratégia de potencialização de autonomia e cidadania nos espaços de atendimento" (PINHO et al., 2013, p. 534). Também apontam como limitação a falta de supervisão e de discussão das práticas grupais entre os profissionais (CAMPOS et al., 2009).

A continuidade do cuidado, representada pela possibilidade de o paciente ser acompanhado pela mesma equipe também nos momentos de crise, permanecendo no leito-noite dos CAPS III, é avaliada positivamente por trabalhadores desse tipo de serviço (CAMPOS et al., 2009). Dificuldades no manejo de crises nos CAPS foram apontadas com relação aos seguintes aspectos: estabelecimento de parcerias com a rede de saúde como um todo (CAMPOS et al., 2009; LIMA et al., 2012); recepção e acompanhamento de pacientes ainda desconhecidos da equipe; especialmente à noite e nos finais de semana (CAMPOS et al., 2009; LIMA et 
1150 al., 2012); estabelecimento de critérios mais bem definidos para a indicação de permanência em leito-noite (CAMPOS et al., 2009; OLSCHOWSKY et al., 2009); utilização de leitos-noite no limite ou acima da capacidade dos serviços (CAMPOS et al., 2009); restrição das equipes nos período noturno e nos finais de semana, basicamente, à equipe de enfermagem, com perda do caráter multidisciplinar (CAMPOS et al., 2009).

A avaliação das gestões municipais pelos trabalhadores variou muito conforme o contexto em foco, havendo avaliações positivas, com gestores percebidos como sensibilizados pelas demandas dos trabalhadores e dispostos a empreender transformações na assistência à saúde mental (HECK et al., 2008) e avaliações negativas, com a percepção de falta de interesse e investimento na atenção à saúde mental (ALVES; DOURADO; CÔRTES, 2013; ATHAYDE; HENNINGTON, 2012; LUZIO; L'ABBATE, 2009). Algumas das queixas mais frequentes relacionavam-se a: contratos de trabalho considerados precários e remuneração considerada insatisfatória (ATHAYDE; HENNINGTON, 2012; GUIMARÃES; JORGE; ASSIS, 2011; KANTORSKI et al., 2009; LUZIO; L'ABBATE, 2009) e inexistência de plano de carreira e salários (CAMPOS et al., 2009). Em relação à gestão mais imediata dos serviços, houve uma demanda praticamente unânime entre os trabalhadores ouvidos em diferentes estudos por capacitação profissional (por exemplo: ALVES; DOURADO; CÔRTES, 2013; ANTUNES; QUEIROZ, 2007; CAMPOS et al., 2009; CONSOLI; HIRDES; COSTA, 2009; MIELKE et al., 2009a).

\section{Perspectiva de usuários e familiares}

As perspectivas de usuários diretos e de familiares de usuários narradas nos artigos convergiram em larga medida. Isso se mostrou não apenas nas pesquisas qualitativas (por exemplo: PINHO et al., 2011), mas também em um estudo quantitativo, no qual a avaliação dos usuários e de seus familiares, em termos de percepção de mudanças ocorridas na vida do usuário em função do tratamento recebido, teve alta porcentagem de concordância (COSTA et al., 2011). Os trabalhos que dão voz aos usuários e familiares, em sua maioria, tiveram os CAPS como campo de pesquisa.

Em relação aos CAPS, usuários e familiares, em geral manifestaram satisfação com os serviços, que tendem a ser percebidos como locais de acolhimento e 
convivência (MIELKE et al., 2012; NASI; SCHNEIDER, 2011; PARANHOSPASSOS; AIRES, 2013; SANTOS et al., 2011). As relaçōes estabelecidas com os trabalhadores são muito valorizadas (CAMPOS et al., 2009; JORGE et al., 2012; SURJUS; CAMPOS, 2011), em especial com o técnico/profissional de referência, quando este arranjo é adotado. Disponibilidade do técnico/profissional de referência e o acompanhamento de necessidades cotidianas e situações de crise são positivamente apreciados (MIRANDA; ONOCKO-CAMPOS, 2011; SANTOS et al., 2011; SURJUS; CAMPOS, 2011). Todavia, o risco de estabelecimento de relações e tutela e de dependência também é apontado (MIRANDA; ONOCKOCAMPOS, 2011; PANDE; AMARANTE, 2011). Uma paciente conta: "Referência é uma pessoa que toma conta da gente. Ela toma conta de mim, ela é minha responsável, é ela que comanda tudo direitinho o que eu tenho que fazer, é ela que arrumou o benefício para mim, que fica com o dinheiro, que controla tudo" (MIRANDA; ONOCKO-CAMPOS, 2010, p. 1.158).

A possibilidade de cuidado à crise no próprio serviço é vista como vantajosa, e o acolhimento noturno e aos finais de semana é considerado imprescindível ao manejo de crises (CAMPOS et al., 2009; LIMA et al., 2012; SURJUS; CAMPOS, 2011). Usuários e familiares queixam-se dos CAPS que não possuem leito-noite (SURJUS; CAMPOS, 2011), mas também, às vezes, do desaparecimento de pertences pessoais durante sua permanência em leito-noite (CAMPOS et al., 2009). Referem-se aos grupos como espaços importantes de trocas e aprendizagem (CAMATTA et al., 2011; CAMPOS et al., 2009; PINHO et al., 2011; SURJUS; CAMPOS, 2011). Os familiares os veem principalmente como dispositivos de apoio, mas queixam-se da falta de flexibilidade nos horários e atividades oferecidos (CAMATTA; SCHNEIDER, 2009; CAMPOS et al., 2011a; PINHO et al., 2013).

Usuários e familiares entrevistados valorizam os espaços de assembleias e iniciativas que visam ao "empoderamento", entendido como "o fortalecimento do poder, participação e organização dos usuários e familiares no âmbito do cuidado nos serviços substitutivos e também nas estratégias de defesa de direitos e no exercício do controle e da militância social" (ALVES; OLIVEIRA; VASCONCELOS, 2013, p. 52; JORGE et al., 2012; ONOCKO-CAMPOS, et al., 2013; PASSOS et al., 2013). Mas também valorizam a forma de organização, de dispensação e orientação relativas à medicação oferecidas em alguns CAPS 
(SURJUS; CAMPOS, 2011) e, em alguns relatos, os cuidados médicos (JORGE et al., 2012; MACHADO; MANÇO; SANTOS, 2005; SOARES; SAEKI, 2006).

\section{Discussão}

Constatamos que, nos últimos dez anos, a produção de dissertações e teses sobre pesquisas avaliativas em saúde mental se reúne em instituições dos estados de São Paulo e Rio de Janeiro, o que obviamente reflete a distribuição dos cursos de pósgraduação no país, bem como sua consolidação institucional, nos casos da USP, UNICAMP e ENSP. A concentração da produção de teses nas áreas de Saúde Coletiva e Enfermagem mostra o interesse e envolvimento na reforma da saúde mental entre os pesquisadores destas áreas, espelha a tradição de avaliação em saúde cultivada especialmente pela Saúde Pública, bem como revela a existência de linhas de pesquisa consolidadas nesta última área, e o incremento da sua produção recente. É relevante indicar que encontramos apenas um trabalho oriundo de pós-graduação em Saúde Mental (área de concentração de Medicina), nenhum em Psiquiatria, e escassas foram as teses levantadas em Psicologia.

Observamos uma alta concentração geográfica dos serviços de saúde mental cuja avaliação é descrita em periódicos científicos. Grande parte dos trabalhos refere-se a um número restrito de municípios localizados nas regiōes Sul e Sudeste do país, alguns dos quais, como Campinas-SP, com características muito particulares em relação à constituição de sua rede de cuidados em saúde mental (QUEIROZ; DELAMUTA, 2011; ONOCKO-CAMPOS et al., 2012) e que, portanto, dificilmente poderiam ser tomados como representantes das condições dos serviços públicos de saúde mental no país. Mesmo dentro de tais municípios, a heterogeneidade dos serviços em relação a aspectos relevantes é apontada (NASCIMENTO; GALVANESE, 2009; CAMPOS et al., 2011a; ONOCKO-CAMPOS et al., 2012). Enfim, considerando a grande diversidade das realidades locais, torna-se imperativa a disseminação nacional de iniciativas de avaliação de serviços.

Tomando o conjunto da produção avaliada (teses, dissertações e artigos), na maioria dos trabalhos os serviços avaliados são os CAPS, o que condiz com a importância deste equipamento na reforma da assistência; a ABS também tem papel relevante na atual política de saúde, o que justifica sua escolha. Um ponto importante do sistema de atenção, os serviços de internação e de emergência, 
também tem sido estudado, mas bem menos frequentemente que as duas instâncias anteriores. Os Serviços Residenciais Terapêuticos são alvo de poucos trabalhos e nota-se a ausência de pesquisas sobre serviços de trabalho protegido ou sobre a reinserção laboral dos usuários. A implantação ou aprimoramento de sistemas de informação específicos em saúde mental, que seriam essenciais para os processos de avaliação, vêm sendo pouco estudados.

$\mathrm{O}$ fato de as fontes de informaçōes mais frequentes serem os trabalhadores de saúde mental (em média, cerca de dois terços do total de estudos), e depois os usuários, indica que o interesse maior da pesquisa avaliativa tem sido depositado nos processos de avaliação e de trabalho, mais do que nos resultados deste último, ou seja, em sua incidência sobre os pacientes (por exemplo, melhoras clínicas, inserção social e qualidade de vida). Nas últimas duas décadas, a inclusão sistemática dos pontos de vista dos usuários e familiares e/ou cuidadores nos processos avaliativos tem sido apontada como importante contribuiçãao para os rumos das pesquisas nos serviços de saúde mental (THORNICROFT; SLADE, 2014), sendo uma recomendação da OMS (2013). ${ }^{4}$ Tal esforço inclusivo pode ser visto nos trabalhos que têm os usuários como foco, e que em geral os consideram de forma participativa.

Vimos que a quase totalidade das pesquisas usa metodologia qualitativa. Essa quase exclusividade na escolha metodológica dos pesquisadores brasileiros faz pensar que, se isso reflete sua intenção de abordar os objetos de pesquisa de forma múltipla e contextualizada, superando a suposta objetividade absoluta dos métodos quantitativos, privilegiando a avaliação participativa e a inclusão de múltiplos atores sociais, e levando em conta os aspectos subjetivos inerentes ao processo saúde-doença - pontos fortes da metodologia qualitativa (MINAYO, 1993; TURATO, 2003) - por outro indica uma polarização que pode ser problemática, pois a desejada abordagem avaliativa abrangente necessita de pluralidade metodológica (HARTZ, 1999) para se concretizar, a fim de produzir evidências sólidas ${ }^{5}$ que direcionem a prática clínica e a organização de serviços.

A articulação dos resultados das pesquisas avaliativas qualitativas, para além das possibilidades de diálogo teórico-conceitual, também no nível empírico, permanece um desafio. A respeito deste ponto, alguns autores, no contexto brasileiro, têm ressaltado a importância e a necessidade de produzir meta-avaliações, ou avaliações das avaliações qualitativas (FURTADO; LAPERRIÈRE, 2011), bem como metassínteses dos resultados das pesquisas 
avaliativas (BARROS et al., 2011), que permitam uma visão compreensiva e crítica da sua qualidade, dos resultados nelas obtidos e de sua aplicabilidade nas políticas e programas de saúde mental.

\section{Conclusões}

A despeito do mérito das contribuições que as pesquisas avaliativas acadêmicas recentes vêm dando para a compreensão do processo de reforma assistencial em curso no país, parece-nos que o conjunto delas não tem a diversidade e a abrangência suficientes para fornecer, em futuro próximo, elementos que possam ser articulados, no sentido de prover indicadores de saúde considerados básicos (OMS, 2013): aqueles que forneçam informações sobre o alcance das políticas, leis, intervenções e serviços (inclusive, indicando a diferença entre o número total de pessoas com transtornos mentais e as que recebem efetivamente tratamento, e que se beneficiam deste); sobre a prevalência dos transtornos mentais, bem como os fatores de risco e proteção; dados quantitativos e qualitativos integrados sobre resultados em saúde mental (tais como taxas de suicídio e de mortalidade precoce; redução de incapacidades e aumento da autonomia dos usuários), além de dados mais gerais sobre resultados sociais e econômicos correlatos (por exemplo, níveis de educação, habitação, emprego e renda das pessoas com transtornos mentais).

Finalmente, tendo em vista que a ética, as evidências científicas e a análise da experiência acumulada podem ser consideradas os pilares de qualquer política ou sistema de saúde mental (THORNICROFT; TANSELLA, 2010), cremos que a configuração do conjunto de pesquisas avaliativas aqui delineada sugere que o peso do investimento investigatório vem sendo distribuído de forma desigual, privilegiando modalidades pouco diversificadas de pesquisa e de análise das experiências relativas ao processo da reforma da assistência em saúde mental. ${ }^{6}$

\section{Referências}

ALVES, H.M. de C.; DOURADO, L.B.R.; CÔRTES, V. da N.Q. A influência dos vínculos organizacionais na consolidação dos Centros de Atenção Psicossociais. Ciênc. saúde colet., Rio de Janeiro, v. 18, n. 10, p. 2965-2975, out. 2013.

ALVES, T.C.; OLIVEIRA, W.F. de; VASCONCELOS, E.M. A visão de usuários, familiares e profissionais acerca do empoderamento em saúde mental. Physis, Rio de Janeiro, v. 23, n. 1, p. 51-71, 2013. 
AMARANTE, A. L. et al. As estratégias dos enfermeiros para o cuidado em saúde mental no Programa Saúde da Família. Texto contexto-enferm., Florianópolis, v. 20, n. 1, p. 8593, mar. 2011.

ANTUNES, S.M.M. de O.; QUEIROZ, M. de S. A configuração da reforma psiquiátrica em contexto local no Brasil: uma análise qualitativa. Cad. Saúde Pública, Rio de Janeiro, v. 23, n. 1, p. 207-215, jan. 2007.

ARAUJO, A.K. de; TANAKA, O.Y. Avaliação do processo de acolhimento em Saúde Mental na região centro-oeste do município de São Paulo: a relação entre CAPS e UBS em análise. Interface (Botucatu), Botucatu, v. 16, n. 43, p. 917-928, dez. 2012.

ATHAYDE, V.; HENNINGTON, E.A. A saúde mental dos profissionais de um Centro de Atenção Psicossocial. Physis, Rio de Janeiro, v. 22, n. 3, p. 983-1001, 2012.

BARROS, M.M.M. de; JORGE, M.S.B.; VASCONCELOS, M.G.F. Experiências de famílias com usuários atendidos em dispositivos de atenção psicossocial. Physis, Rio de Janeiro, v. 23, n. 3, p. 821-841, set. 2013.

BARROS, N.F. et al. A produção de sínteses com evidências qualitativas: uma revisão de métodos e técnicas. In: ONOCKO-CAMPOS, R.T.; FURTADO, J.P. (Org.). Desafios da avaliação de programas e serviços em saúde. Campinas: Unicamp, 2011. p. 19-37.

BIELEMANN, V. de L.M. et al. A inserção da família nos Centros de Atenção Psicossocial sob a ótica de seus atores sociais. Texto contexto-enferm., Florianópolis, v. 18, n. 1, p. 131139, mar. 2009.

BRASIL. Ministério da Saúde. Portaria n. 224/SNAS, de 29 de janeiro de 1992. Estabelece diretrizes e normas para o atendimento ambulatorial, Núcleos e Centros de Atenção Psicossocial e normas para ao atendimento hospitalar. Disponível em: <http://www.saude. sc.gov.br/geral/planos/programas_e_projetos/saude_mental/portaria_n224.htm>. Acesso em: 30 jul. 2014.

BRASIL. Ministério da Saúde. Lei n. 10.216, de 6 de abril de 2001. Dispõe sobre a proteção e os direitos das pessoas portadoras de transtornos mentais e redireciona o modelo assistencial em saúde mental. Disponível em: <http://www.planalto.gov.br/ccivil_03/leis/leis_2001/ 110216.htm>. Acesso em: 30 jul. 2014.

BRASIL. Ministério da Saúde. Portaria n. 336/GM/MS, de 19 de fevereiro de 2002. Estabelece as modalidades dos Centros de Atenção Psicossocial, etc. Disponível em: <http:// dtr2004.saude.gov.br/susdeaz/legislacao/arquivo/39_Portaria_336_de_19_02_2002.pdf>. Acesso em: 30 jul. 2014.

BRASIL. Ministério da Saúde. Secretaria de Atenção à Saúde/DAPE. Saúde Mental no SUS: acesso ao tratamento e mudança do modelo da atenção. Relatório de Gestão 2003-2006. Brasília: Ministério da Saúde, 2007. 78 p. 
BRASIL. Ministério da Saúde. Portaria n. 3.088, de 23 de dezembro de 2011. (Republicada em 31 de dezembro de 2011). Institui a Rede de Atenção Psicossocial para pessoas com sofrimento ou transtorno mental e com necessidades decorrentes do uso de crack, álcool e outras drogas, no âmbito do Sistema Único de Saúde (SUS). Disponível em: <http://bvsms.saude.gov.br/ bvs/saudelegis/gm/2011/prt3088_23_12_2011_rep.html>. Acesso em: 30 jul. 2014.

CALGARO, A.; SOUZA, E.N. de. Percepção do enfermeiro acerca da prática assistencial nos serviços públicos extra-hospitalares de saúde mental. Revista Gaúcha de Enfermagem, Porto Alegre, v. 30, n. 3, p. 476-483, 2009.

CAMATTA, M.W. et al. Avaliação de um Centro de Atenção Psicossocial: o olhar da família. Ciênc. saúde colet., Rio de Janeiro, v. 16, n. 11, p. 4405-4414, 2011.

CAMATTA, M. W.; SCHNEIDER, J. F. A visão da família sobre o trabalho de profissionais de saúde mental de um Centro de Atenção Psicossocial. Esc. Anna Nery, Rio de Janeiro, v.13, n.3, p.477-484, 2009.CAMPOS, G.W. de S.; ONOCKO-CAMPOS, R.T.; DEL BARRIO, L.R. Políticas e práticas em saúde mental: as evidências em questão. Ciênc. saúde colet., Rio de Janeiro, v. 18, n. 10, p. 2797-2805, out. 2013.

CAMPOS, R.T.O. et al. Avaliação da rede de Centros de Atenção Psicossocial: entre a saúde coletiva e a saúde mental. Rev. Saúde Públ., São Paulo, v. 43, supl. 1, p. 16-22, ago. 2009.

CAMPOS, R.O.; BACCARI, I.P. A intersubjetividade no cuidado à Saúde Mental: narrativas de técnicos e auxiliares de enfermagem de um Centro de Atenção Psicossocial. Ciênc. saúde colet., Rio de Janeiro, v. 16, n. 4, p. 2051-2058, abr. 2011.

CAMPOS, R.O. et al. Saúde mental na atenção primária à saúde: estudo avaliativo em uma grande cidade brasileira. Ciênc. saúde colet., Rio de Janeiro, v. 16, n. 12, p. 46434652, dez. 2011a.

CARVAlHO, M.D.A. de; SILVA, H.O.; RODRIGUES, L.V. Perfil epidemiológico dos usuários da rede de saúde mental do município de Iguatu, CE. SMAD, Rev. Eletrônica Saúde Mental Álcool Drog., Ribeirão Preto, v. 6, n. 2, p. 337-349, 2010.

CAVALCANTE, C.M.; JORGE, M.S.B.; SANTOS, D.C.M. dos. Onde está a criança? Desafios e obstáculos ao apoio matricial de crianças com problemas de saúde mental. Physis, Rio de Janeiro, v. 22, n. 1, p. 161-178, 2012.

CONSELHO REGIONAL DE MEDICINA DO ESTADO DE SÃO PAULO. Avaliação dos Centros de Atenção Psicossocial (CAPS) do Estado de São Paulo. Coordenação Institucional de Mauro Gomes Aranha de Lima. São Paulo: Conselho Regional de Medicina do Estado de São Paulo, 2010. 104 p.

CONSOLI, G.L.; HIRDES, A.; COSTA, J.S. D. da. Saúde mental nos municípios do Alto Uruguai, RS, Brasil: um diagnóstico da reforma psiquiátrica. Ciênc. saúde colet., Rio de Janeiro, v. 14, n. 1, p. 117-128, fev. 2009. 
COSTA, C.S. et al. A percepção de pacientes e familiares sobre os resultados do tratamento em serviços de saúde mental. Cad. Saúde Pública, Rio de Janeiro, v. 27, n. 5, p. 995-1007, maio 2011.

COUTO, M.C.V.; DUARTE, C.S.; DELGADO, P.G.G. A saúde mental infantil na Saúde Pública brasileira: situação atual e desafios. Rev. Bras. Psiquiatr., Rio de Janeiro, v. 30, n. 4, p. 384-389, dez. 2008.

DECS. Descritores em Ciências da Saúde. Avaliação em Saúde. Disponível em: <http://decs. bvs.br/cgi-bin/wxis1660.exe/decsserver/>. Acesso em: 01 jul. 2014.

DELFINI, P.S. de S.; REIS, A.O. A. Articulação entre serviços públicos de saúde nos cuidados voltados à saúde mental infantojuvenil. Cad. Saúde Pública, Rio de Janeiro, v. 28, n. 2, p. 357-366, fev. 2012.

DELGADO, P.G. Como tornar melhores os Serviços de Saúde Mental? (Apresentação). In: THORNICROFT, G.; TANSEllA, M. (Org.). Boas práticas em Saúde Mental Comunitária. Barueri: Manole, 2010. p. XII-XV.

FIGUEIREDO, M.D.; CAMPOS, R. Saúde Mental na atenção básica à saúde de Campinas, SP: uma rede ou um emaranhado? Ciênc. saúde colet., Rio de Janeiro, v. 14, n. 1, p. 129-138, fev. 2009.

FIORATI, R.C.; SAEKI, T. Predominância da tecnologia médico-clínica sobre ações de atenção psicossocial em serviços extra-hospitalares de saúde mental. Ciênc. saúde colet., Rio de Janeiro, v. 18, n. 10, p. 2957-2963, out. 2013.

FURTADO, J.P.; LAPERRIÈRRE, H. A avaliação da avaliação. In: ONOCKOCAMPOS, R.T.; FURTADO, J.P. (Org.). Desafios da avaliação de programas e serviços em saúde. Campinas: Editora da Unicamp, 2011. p. 19-37.

FURTADO, J.P. et al. A elaboração participativa de indicadores para a avaliação em saúde mental. Cad. Saúde Pública, Rio de Janeiro, v. 29, n. 1, p. 102-110, jan. 2013.

GALVANESE, A.T.C.; NASCIMENTO, A. de F.; D’OLIVEIRA, A.F.P.L. Arte, cultura e cuidado nos Centros de Atenção Psicossocial. Rev. Saúde Públ., São Paulo,v. 47, n. 2, p. 360-7, abr. 2013.

GUIMARÃES, J.M.X.; JORGE, M.S.B.; ASSIS, M.M.A. (In)satisfação com o trabalho em saúde mental: um estudo em Centros de Atenção Psicossocial. Ciênc. saúde colet., Rio de Janeiro, v. 16, n. 4, p. 2.145-2.154, abr. 2011.

HARTZ, Z.M.A. Avaliação dos programas de saúde: perspectivas teórico-metodológicas e políticas institucionais. Ciênc. saúde colet., Rio de Janeiro, v. 4, n. 2, p. 341-353, 1999.

HARTZ, Z.M.A. Princípios e padrões em meta-avaliação: diretrizes para os programas de saúde. Ciênc. saúde colet., Rio de Janeiro, v. 11, n. 3, p. 733-738, set. 2006. 
HECK, R.M. et al. Gestão e saúde mental: percepções a partir de um Centro de Atenção Psicossocial. Texto contexto-enferm., Florianópolis, v. 17, n. 4, p. 647-655, dez. 2008.

HOFFMANN, M.C.C.L.; SANTOS, D.N.; MOTA, E.L.A. Caracterização dos usuários e dos serviços prestados por Centros de Atenção Psicossocial Infanto-Juvenil. Cad. Saúde Pública, Rio de Janeiro, v. 24, n. 3, p. 633-642, mar. 2008.

JORGE, M.S.B. et al. Experiências com a gestão autônoma da medicação: narrativa de usuários de saúde mental no encontro dos grupos focais em Centros de Atenção Psicossocial. Physis, Rio de Janeiro, v. 22, n. 4, p. 1543-1561, 2012.

JORGE, M.S.B. et al. Promoção da Saúde Mental: tecnologias do cuidado: vínculo, acolhimento, corresponsabilização e autonomia. Ciênc. saúde colet., Rio de Janeiro, v. 16, n. 7, p. 3.051-3.060, 2011.

JUCÁ, V.J. dos S.; NUNES, M. de O.; BARRETO, S.G. Programa de Saúde da Família e Saúde Mental: impasses e desafios na construção da rede. Ciênc. saúde colet., Rio de Janeiro, v. 14, n. 1, p. 173-182, fev. 2009.

KANTORSKI, L.P. et al. Contribuições do Estudo de Avaliação dos Centros de Atenção Psicossocial da Região Sul do Brasil. Cad. Bras. Saúde Mental, Florianópolis, v. 1, n. 1, p. 202-211, 2009.

KILSZTAJN, S. et al. Leitos hospitalares e reforma psiquiátrica. Cad. Saúde Pública, Rio de Janeiro, v. 24, n. 10, p. 2.354-2.362, 2008.

LIMA, M. et al. Signos, significados e práticas de manejo da crise em Centros de Atenção Psicossocial. Interface (Botucatu), Botucatu, v. 16, n. 41, p. 423-434, jun. 2012.

LUZIO, C.A.; L’ABBATE, S. A atenção em Saúde Mental em municípios de pequeno e médio portes: ressonâncias da reforma psiquiátrica. Ciênc. saúde colet., Rio de Janeiro, v. 14, n. 1, p. 105-116, fev. 2009.

MACHADO, V.; MANÇO, A.R.X.; SANTOS, M.A.D dos. A recusa à desospitalização psiquiátrica: um estudo qualitativo. Cad. Saúde Pública, Rio de Janeiro, v. 21, n. 5, p. $1.472-$ 1.479, out. 2005.

MARI, J.J. et al. Mental health research in Brazil: policies, infrastructure, financing and human resources. Rev. Saúde Públ., São Paulo, v. 40, n. 1, p. 161-169, fev. 2006.

MARI, J.J.; THORNICROFT, G. Princípios que deveriam nortear as políticas de saúde mental em países de baixa e média rendas. Rev.Bras. Psiq., Rio de Janeiro, v. 32, n. 3, p. 212-213, 2010.

MATEUS, M.D. et al. The mental health system in Brazil: policies and future challenges. Int. J. Ment. Health Syst., London, v. 2, n. 1, p. 12-19, jan. 2008.

MERHY, E. O ato de governar as tensões constitutivas do agir em saúde como desafio permanente de algumas estratégias gerenciais. Ciênc. saúde colet., Rio de Janeiro, v.4, n.2, p.305-14, 1999. 
MIELKE, F.B. et al. Avaliação de um serviço substitutivo em saúde mental. Cogitare enferm., Curitiba, v. 14, n. 1, p. 52-8, 2009a.

MIELKE, F.B. et al. O cuidado em saúde mental no CAPS no entendimento dos profissionais. Ciênc. saúde colet., Rio de Janeiro, v. 14, n. 1, p. 159-164, fev. 2009 b.

MIELKE, F.B.; OLCHOWSKY, A. Saúde mental na Estratégia Saúde da Família: a avaliação de apoio matricial. Rev Bras Enferm, Brasília, v. 63, n. 6, p. 900-907, dez. 2010.

MIELKE, F.B. et al. Avaliação qualitativa da relação de atores sociais com a loucura em um serviço substitutivo de saúde mental. Rev Bras Enferm, Brasília, v. 65, n. 3, p. 501-507, jun. 2012. MINAYO, M.C.S. O desafio do conhecimento: pesquisa qualitativa em saúde. São Paulo: Hucitec, 1993. 269 p.

MIRANDA, L.; ONOCKO-CAMPOS, R.T. Análise das equipes de referência em saúde mental: uma perspectiva de gestão da clínica. Cad. Saúde Pública, Rio de Janeiro, v. 26, n. 6, p. 1.153-1.162, jun. 2010.

NARDI, H.C.; RAMMINGER, T. Modos de subjetivação dos trabalhadores de saúde mental em tempos de Reforma Psiquiátrica. Physis, Rio de Janeiro, v. 17, n. 2, p. 265-287, 2007.

NASCIMENTO, A. de F.; GALVANESE, A.T.C. Avaliação da estrutura dos Centros de Atenção Psicossocial do município de São Paulo, SP. Rev. Saúde Públ., São Paulo, v. 43, supl. 1, p. 8-15, ago. 2009.

NASI, C.; SCHNEIDER, J.F.O Centro de Atenção Psicossocial no cotidiano dos seus usuários. Rev Esc Enferm USP, São Paulo, v. 45, n. 5, p. 1.157-1.163, out. 2011.

NUNES, M.; JUCÁ, V.J.; VALENTIM, C.P.B. Ações de saúde mental no Programa Saúde da Família: confluências e dissonâncias das práticas com os princípios das reformas psiquiátrica e sanitária. Cad. Saúde Pública, Rio de Janeiro, v. 23, n. 10, p. 2.375-2.384, out. 2007.

NUNES, M. et al. A dinâmica do cuidado em saúde mental: signos, significados e práticas de profissionais em um Centro de Assistência Psicossocial em Salvador, Bahia, Brasil. Cad. Saúde Pública, Rio de Janeiro, v. 24, n. 1, p. 188-196, jan. 2008.

OLSCHOWSKY, A. et al. Avaliação de um Centro de Atenção Psicossocial: a realidade em Foz do Iguaçu. Rev Esc Enferm USP, São Paulo, v. 43, n. 4, p. 781-787, dez. 2009.

ONOCKO-CAMPOS, R.T. Pesquisa em Saúde Mental no Brasil: through the looking-glass. Ciênc. saúde colet., Rio de Janeiro, v. 16, n. 4, p. 2032-2032, abr. 2011.

ONOCKO-CAMPOS, R.T. et al. A Gestão Autônoma da Medicação: uma intervenção analisadora de serviços em saúde mental. Ciênc. saúde colet., Rio de Janeiro, v. 18, n. 10, p. 2.889-2.898, out. 2013.

ONOCKO-CAMPOS, R. T. et al. Avaliação de estratégias inovadoras na organização da Atenção Primária à Saúde. Rev. Saúde Públ., São Paulo, v. 46, n. 1, p. 43-50, fev. 2012. 
ORGANIZACIÓN MUNDIAL DE LA SALUD. Plan de acción sobre Salud Mental 20132020. OMS: Ginebra, 2013.

PANDE, M.N.R.; AMARANTE, P.D. de C. Desafios para os Centros de Atenção Psicossocial como serviços substitutivos: a nova cronicidade em questão. Ciênc. saúde colet., Rio de Janeiro, v. 16, n. 4, p. 2.067-2.076, abr. 2011.

PARANHOS-PASSOS, F.; AIRES, S. Reinserção social de portadores de sofrimento psíquico: o olhar de usuários de um Centro de Atenção Psicossocial. Physis, Rio de Janeiro v. 23, n. 1, p. 13-31, 2013.

PASSOS, E. et al. O Comitê Cidadão como estratégia cogestiva em uma pesquisa participativa no campo da saúde mental. Ciênc. saúde colet., Rio de Janeiro, v. 18, n. 10, p. 2.919-2.928, out. 2013.

PEREIRA, P.K. et al. Transtornos mentais e comportamentais no Sistema de Informações Hospitalares do SUS (SIH-SUS) no estado do Rio de Janeiro no período de 1999 a 2010. Cad. Saúde Coletiva, Rio de Janeiro, v. 20, n. 4, p. 482-491, 2012.

PINHO, L.B. de; HERNÁNDEZ, A.M.B.; KANTORSKI, L.P. Serviços substitutivos de saúde mental e inclusão no território: contradições e potencialidades. Cienc. Cuid. Saude, Maringá, v. 9, n. 1, p. 28-35, jul. 2010.

PINHO, L.B. de et al. Atividades terapêuticas: compreensão de familiares e profissionais de um centro de atenção psicossocial. Esc Anna Nery, Rio de Janeiro, v. 17, n. 3, p. 534-541, set. 2013.

PINHO, L.B. de et al. Avaliação qualitativa do processo de trabalho em um Centro de Atenção Psicossocial no Brasil. Rev. Panam. Salud Públ., Washington DC, v. 30, n. 4, p. 354-360, 2011.

PINTO, A.G.A. et al. Apoio matricial como dispositivo do cuidado em saúde mental na atenção primária: olhares múltiplos e dispositivos para resolubilidade. Ciênc. saúde colet., Rio de Janeiro, v. 17, n. 3, p. 653-660, mar. 2012.

QUEIROZ, M. de S.; DELAMUTA, L.A. Saúde mental e trabalho interdisciplinar: a experiência do "Cândido Ferreira" em Campinas. Ciênc. saúde colet., Rio de Janeiro, v. 16, n. 8, p. 3.603-3.612, ago. 2011.

QUINDERÉ, P.H.D. et al. Acessibilidade e resolubilidade da assistência em saúde mental: a experiência do apoio matricial. Ciênc. saúde colet., Rio de Janeiro, v. 18, n. 7, p. 2.1572.166, jul. 2013.

RIBEIRO, L.M. et al. Saúde mental e enfermagem na Estratégia Saúde da Família: como estão atuando os enfermeiros? Rev Esc Enferm USP, São Paulo, v. 44, n. 2, p. 376-382, jun. 2010.

RIBEIRO, M. S. et al. Comparação da assistência em saúde mental em unidades básicas de saúde com ou sem equipe do Programa de Saúde da Família. Rev. psiquiatr. Rio Grande do Sul, Porto Alegre, v. 31, n. 1, p. 40-50, 2009. 
SCHMIDT, M.B.; FIGUEIREDO, A. C. Acesso, acolhimento e acompanhamento: três desafios para o cotidiano da clínica em saúde mental. Rev. latinoam. psicopatol. fundam., São Paulo, v. 12, n. 1, p. 130-140, 2009.

SILVA, M.B.B. e. Atenção psicossocial e gestão de populaçôes: sobre os discursos e as práticas em torno da responsabilidade no campo da saúde mental. Physis, Rio de Janeiro, v. 15, n. 1, p. 127-150, jun. 2005.

SILVA, M.T. da; LANCMAN, S.; ALONSO, C.M. do C. Conseqüências da intangibilidade na gestão dos novos serviços de saúde mental. Rev. Saúde Públ., São Paulo, v. 43, supl. 1, p. 33-42, ago. 2009.

SOARES, S.R.R.; SAEKI, T. The Psychosocial Care Center on the users point of view. Rev. Latino-Am. Enfermagem, Ribeirão Preto, v. 14, n. 6, p. 923-929, dez. 2006.

SOUSA, F.S.P. de et al. Tecendo a rede assistencial em saúde mental com a ferramenta matricial. Physis, Rio de Janeiro, v. 21, n. 4, p. 1.579-1.599, dez. 2011.

SURJUS, L.T. de L.; CAMPOS, R. O. A avaliação dos usuários sobre os Centros de Atenção Psicossocial (CAPS) de Campinas, SP. Rev. latinoam. psicopatol. fundam., São Paulo, v. 14, n. 1, p. 122-133, mar. 2011.

TANAKA, O.Y.; LAURIDSEN-RIBEIRO, E. Desafio para a atenção básica: incorporação da assistência em saúde mental. Cad. Saúde Pública, Rio de Janeiro, v. 22, n. 9, p. 1.8451.853, 2006.

TANAKA, O.Y.; RIBEIRO, E.L. Ações de saúde mental na atenção básica: caminho para ampliação da integralidade da atenção. Ciênc. saúde colet., Rio de Janeiro, v. 14, n. 2, p. 477-486, abr. 2009.

TAVARES, C.M. de M.; SOBRAL, V.R.S. Avaliação das práticas de cuidar envolvendo arte no âmbito do Centro de Atenção Psicossocial (CAPS). REME - Revista Mineira de Enfermagem, Belo Horizonte, v. 9, n. 2, p. 121-125, 2005.

THORNICROFT, G.; TANSELLA, M. Boas práticas em Saúde Mental Comunitária. Barueri: Manole, 2010. 179 p.

THORNICROFT, G.; SLADE, M. New trends in assessing the outcomes of mental health interventions. World Psychiatry, v. 13, n. 2, p. 118-24, jun. 2014.

TÓFOLI, L.F.; FORTES, S. Apoio Matricial de Saúde Mental no Município de Sobral, CE: o relato de uma experiência. SANARE, Sobral, v. 6, n. 2, p. 34-42, 2007.

TURATO, E.R. Tratado da metodologia da pesquisa clinico-qualitativa. Petrópolis: Vozes, 2003. $688 \mathrm{p}$.

WETZEL, C.; KANTORSKI, L.P. Avaliação de serviços em saúde mental no contexto da reforma psiquiátrica. Texto contexto-Enferm., Florianópolis, v. 13, n. 4, p. 543-548, dez. 2004. WETZEL, C. et al. Dimensões do objeto de trabalho em um Centro de Atenção Psicossocial. Ciênc. saúde colet., Rio de Janeiro, v. 16, n. 4, p. 2.133-2.143, abr. 2011. 
WORLD HEALTH ORGANIZATION. ASSESSMENT INSTRUMENT FOR MENTAL HEALTH SYSTEMS. Report on Mental Health System in Brazil. WHO and Ministry of Health: Brasília, Brazil, 2007. 51 p.

ZAMBEnEDETTI, G.; PERRONE, C.M. O Processo de construção de uma rede de atenção em Saúde Mental: desafios e potencialidades no processo de Reforma Psiquiátrica. Physis, Rio de Janeiro, v. 18, n. 2, p. 277-293, 2008.

\section{Levantamento sobre pesquisa avaliativa em saúde mental Dissertaçôes e teses}

ALVES, T.C. Dispositivos de empoderamento em saúde mental de um Centro de Atenção Psicossocial. 2012. 146 p. Dissertação (Mestrado em Saúde Coletiva) - Universidade Federal de Santa Catarina, Florianópolis, 2012. Disponível em: https://repositorio.ufsc.br/ bitstream/handle/123456789/100925/310988.pdf? sequence=1. Acesso em: 01 jul. 2014.

ARAUJO, A.K de. Avaliação em saúde mental: o processo de acolhimento. 2012. 138 p. Dissertação (Mestrado em Saúde Pública) - Faculdade de Saúde Pública, Universidade de São Paulo, São Paulo, 2012. Disponível em: http://www.teses.usp.br/teses/disponiveis/6/6135/ tde-15032012-101652/publico/AdrianoKasiorowski.pdf. Acesso em: 01 jul. 2014.

BARROS, M.M.M de. Experiências das famílias com usuários atendidos nos dispositivos de atenção psicossocial. 2012. 207 p. Tese. (Doutorado em Saúde Coletiva) - Universidade Estadual do Ceará, Fortaleza, 2012. Disponível em: http://www.uece.br/dsc/index.php/ arquivos/doc_download/171-tese-marcia-pdf. Acesso em: 01 jul. 2014.

BARROS, R. E. M. Reinternações psiquiátricas: influência de variáveis sócio-demográficas, clínicas e de modalidades de tratamento. 2012. 191 p. Tese (Doutorado em Medicina, área de Saúde Mental) - Faculdade de Medicina de Ribeirão Preto, Universidade de São Paulo, Ribeirão Preto, 2012. Disponível em: http://www.teses.usp.br/teses/disponiveis/17/17148/ tde-12112012-225207/pt-br.php. Acesso em: 01 jul. 2014.

BECKER, S.G. O Cotidiano do cuidado em saúde mental. 2012. 163 p. Tese (Doutorado em Enfermagem) - Universidade Federal de Santa Catarina, Florianópolis, 2012. Disponível em: $\quad$ http://repositorio.ufsc.br/xmlui/bitstream/handle/123456789/96457/304614. pdf? sequence $=1$ \&isAllowed $=y>$. Acesso em: 01 jul. 2014 .

BEDIN, B.V. Reflexões sobre práticas grupais nos CAPS. 2009. 118 p. Dissertação (Mestrado em Saúde Coletiva) - Universidade Estadual de Campinas, Campinas, 2009. Disponível em: http://www.fcm.unicamp.br/fcm/sites/default/files/dissertacao_bianca_bedin_0.pdf. Acesso em: 01 jul. 2014.

BOTTI, N.C.L. Oficinas em saúde mental: história e função. 2004. 244 p. Tese (Doutorado em Enfermagem) - Escola de Enfermagem de Ribeirão Preto, Universidade de São Paulo, 
Ribeirão Preto, 2004. Disponível em: http://www.teses.usp.br/teses/disponiveis/22/22131/ tde-26072004-114940/publico/TESE.pdf. Acesso em: 01 jul. 2014.

BRANCO, A.B. de A. C. Integralidade e humanização em saúde mental: experiências de usuários em dois Centros de Atenção Psicossocial. 2012. S/n p. Dissertação (Mestrado em Saúde Pública) - Universidade Federal do Ceará, Fortaleza, 2012. Disponível em: http:// capesdw.capes.gov.br/?login-url-success=/capesdw/. Acesso em: 01 jul. 2014.

BRITTO, R.C. Reflexóes acerca da garantia de proteção aos direitos da pessoa com transtorno mental. 2004. 210 p. Dissertação (Mestrado em Saúde Pública) - Escola Nacional de Saúde Pública Sérgio Arouca, Fundação Oswaldo Cruz, Rio de Janeiro, 2004. Disponível em: http://pesquisa.bvsalud.org/portal/resource/pt/lil-415924. Acesso em: 01 jul. 2014.

CAMATTA, M.W. Açôes voltadas para saúde mental na Estratégia de Saúde da Família: intençôes de equipes e expectativas de usuários e familiares. 2010. 207 p. Tese (Doutorado em Enfermagem) - Universidade Federal do Rio Grande do Sul, Porto Alegre, 2010. Disponível em: http://www.bibliotecadigital.ufrgs.br/da.php?nrb=000767787\&loc =2011\&l=d7d1c62 039ec3d82. Acesso em: 01 jul. 2014.

CAYRES, A.Z. de F. Projetos terapêuticos dos Centros de Atenção Psicossocial para crianças e adolescentes (CAPS-i) do município de São Paulo na perspectiva dos trabalhadores de saúde mental. 2008. 251 p. Dissertação (Mestrado em Saúde Pública) - Faculdade de Saúde Pública, Universidade de São Paulo, São Paulo, 2008. Disponível em: http://pesquisa. bvsalud.org/portal/resource/pt/lil-511035. Acesso em: 01 jul. 2014.

CORREA, S.G. de P. Avaliação de novos serviços de saúde mental: o caso dos Centros de Atenção Psicossocial do Estado do Rio de Janeiro. 2011. 93 p. Dissertação (Mestrado em Ciências na área de Saúde Pública) - Escola Nacional de Saúde Pública Sérgio Arouca, Fundação Oswaldo Cruz, Rio de Janeiro, 2011. Disponível em: http://bvssp.icict.fiocruz. br/lildbi/docsonline/get.php?id=3047. Acesso em: 01 jul. 2014.

CRUZ, M.C.L. Serviços residenciais terapêuticos do Instituto de Psiquiatria da Universidade Federal do Rio de Janeiro e o serviço social: a busca pela desinstitucionalização e autonomia dos usuários. 2012. 188 p. Dissertação (Mestrado em Serviço Social) - Pontifícia Universidade Católica do Rio de Janeiro, Rio de Janeiro, 2012. Disponível em: http://www2.dbd.puc-rio. br/pergamum/tesesabertas/1011777_2012_completo.pdf. Acesso em: 01 jul. 2014.

DAMÁSIO, V.F. O cuidado na desinstitucionalização sob o olhar de ex-internas e seus familiares. 2006. 160 p. Dissertação (Mestrado em Enfermagem) - Universidade do Estado do Rio de Janeiro, Rio de Janeiro, 2006. Disponível em: http://pesquisa.bvsalud.org/portal/ resource/pt/lil-507932. Acesso em: 01 jul. 2014.

DIAZ, A.R.G. Atenção à crise em Saúde Mental: clínica, planejamento e gestão. 2013. 189 p. Tese (Doutorado em Saúde Coletiva) - Universidade Estadual de Campinas, Campinas, 2013. Disponível em: http://www.fcm.unicamp.br/fcm/sites/default/files/tese_tato_diaz. pdf. Acesso em: 28 jul. 2014. 
DIAZ, A.R.G. Pesquisa avaliativa em Saúde Mental: a regulação da porta nos CAPS. 2009. 148 p. Dissertação (Mestrado em Saúde Coletiva) - Universidade Estadual de Campinas, Campinas, 2009. Disponível em: http://www.fcm.unicamp.br/fcm/sites/default/files/ dissertacao_tato_0.pdf. Acesso em: 28 jul. 2014.

DUARTE, M.J. de O. O processo de construção do campo psicossocial na política de saúde mental: uma análise micropolítica da produção do cuidado. 2012. 276 p. Tese (Doutorado em Serviço Social) - Universidade do Estado do Rio de Janeiro, Rio de Janeiro, 2012. Disponível em: http://capesdw.capes.gov.br/?login-url-success=/capesdw/. Acesso em: 01 jul. 2014.

ELIAS, A.D. da S. 2012. Cuidado de enfermagem ao paciente psiquiátrico em situação de emergência geral: real e imaginário. 2012. 106 p. Dissertação (Mestrado Profissional em Enfermagem) - Universidade Federal Fluminense, Niterói, 2012. Disponível em: http:// www.bdtd.ndc.uff.br/tde_arquivos/32/TDE-2013-03-04T142159Z-3547/Publico/ Andrea\%20Damiana.pdf. Acesso em: 01 jul. 2014.

ELIAS, L. de A. Um estudo de caso da implementação de um Centro de Atenção Psicossocial em álcool e drogas (CAPS-ad), no Rio de Janeiro, 2009-2010. 2011. 114p. Tese (Doutorado em Ciências, área de Saúde Pública) - Escola Nacional de Saúde Pública Sérgio Arouca, Fundação Oswaldo Cruz, Rio de Janeiro, 2011. Disponível em: http://bvssp.icict.fiocruz. br/lildbi/docsonline/get.php?id=2486 . Acesso em: 16 jul. 2014.

FERRER, A.L. A Saúde Mental na Atenção Básica sob a perspectiva de trabalhadores e usuários dos serviços: um estudo hermenêutico-narrativo sobre os processos de acolhimento, vínculo e responsabilização. 2012. 228 p. Tese (Doutorado em Saúde Coletiva) - Universidade Estadual de Campinas, Campinas, 2012. Disponível em: http://www.fcm.unicamp.br/fcm/ sites/default/files/tese_ana_luiza.pdf. Acesso em: 28 jul. 2014.

FIGUEIREDO, M.D. O apoio matricial de saúde mental na rede básica de Campinas/ SP. 2006. 168 p. Dissertação (Mestrado em Saúde Coletiva) - Universidade Estadual de Campinas, Campinas, 2006. Disponível em: http://www.bibliotecadigital.unicamp.br/ document/?down=000370049. Acesso em: 28 jul. 2014.

FONSECA, M.H. C. da. Custos e qualidade de vida de duas populaçôes - moradores de residências terapêuticas e pacientes de longa permanência de hospitais psiquiátricos do município do Recife (PE): um estudo exploratório. 2011. Dissertação (Mestrado Profissional em Avaliação em Saúde) - Instituto de Medicina Integral Professor Fernando Figueira, Recife, 2011. Disponível em: http://capesdw.capes.gov.br/?login-url-success=/capesdw/ . Acesso em: 01 jul. 2014.

FREIRE, F.H.M. de A. Cartografia do financiamento em saúde mental: modelagens na Rede de Atenção Psicossocial na relação do cuidado à loucura. 2012. 255 p. Tese (Doutorado em Saúde Pública) - Escola Nacional de Saúde Pública Sérgio Arouca, Fundação Oswaldo Cruz, Rio de Janeiro, 2012. Disponível em: http://bvssp.icict.fiocruz.br/lildbi/docsonline/ get.php?id=3356. Acesso em: 01 jul. 2014. 
GAMA, C.A.P da. Saúde Mental na Atenção Básica: as relaçôes entre a subjetividade e o território. 2011. 192 p. Tese (Doutorado em Saúde Coletiva) - Universidade Estadual de Campinas, Campinas, 2011. Disponível em: http://www.fcm.unicamp.br/fcm/sites/ default/files/tese_carlos_gama.pdf. Acesso em: 01 jul. 2014.

GOMES, N.A. Critérios utilizados por trabalhadores para a inclusão de adolescentes em serviços públicos de saúde mental. 2009. 166 p. Dissertação (Mestrado em Saúde Pública) Faculdade de Saúde Pública, Universidade de São Paulo, São Paulo, 2009. Disponível em: http://pesquisa.bvsalud.org/portal/resource/pt/lil-553125. Acesso em: 01 jul. 2014.

GONÇALVES, L.L.M. A gestão autônoma da medicação numa experiência com usuários militantes da saúde mental. 2013. 256 p. Tese (Doutorado em Saúde Coletiva) - Universidade Estadual de Campinas, Campinas, 2013. Disponível em: http://www.bibliotecadigital. unicamp.br/document/?code=000908438. Acesso em: 01 jul. 2014.

GUIMARÃES, A.N. A prática em saúde mental do modelo manicomial ao psicossocial: história contada por profissionais de enfermagem. 2011. 212 p. Dissertação (Mestrado em Enfermagem) - Universidade Federal do Paraná, Curitiba, 2011. Disponível em: http:// www.ppgenf.ufpr.br/DissertacaoAndreaGuimaraes.pdf. Acesso em: 01 jul. 2014.

GUIMARÃES, J.M.X. Inovação e gestão em serviços de saúde mental: incorporação de tecnologias e reinvenção no cotidiano dos Centros de Atenção Psicossocial. 2012. 286 p. Tese (Doutorado em Saúde Coletiva) - Universidade Estadual do Ceará, Fortaleza, 2012. Disponível em: http://www.uece.br/dsc/index.php/arquivos/doc_download/180-josemaria-ximenes-guimaraes. Acesso em: 01 jul. 2014.

KOHLRAUSCH, E.R. Avaliação das açôes de saúde mental relacionadas ao indivíduo com comportamento suicida na Estratégia de Saúde da Família. 2012. 197 p. Tese (Doutorado em Enfermagem) - Universidade Federal do Rio Grande do Sul, Porto Alegre, 2012. Disponível em: http://www.bibliotecadigital.ufrgs.br/da.php? $\mathrm{nrb}=000873068 \&$ loc $=2013 \& \mathrm{l}=\mathrm{b} 623 \mathrm{~b} 9$ ebb4148589. Acesso em: 01 jul. 2014.

LEMOS, P.M. Consideraçôes éticas sobre o Centro de Atenção Psicossocial no contexto cearense: o olhar do supervisor clínico institucional. 2012. 184 p. Dissertação (Mestrado em Psicologia) - Universidade Federal do Ceará, Fortaleza, 2012. Disponível em: http://www.repositorio. ufc.br/handle/riufc/6816. Acesso em: 01 jul. 2014.

LISBOA, M.S. Os loucos de rua e as redes de saúde mental: os desafios do cuidado no território e a armadilha da institucionalização. 2013. 281 p. Tese (Doutorado em Psicologia) - Pontifícia Universidade Católica de São Paulo, São Paulo, 2013. Disponível em: http://sms.sp.bvs.br/ lildbi/docsonline/get.php?id=4228. Acesso em: 01 jul. 2014.

LUCCHESI, M. Estudo da viabilidade da implantação de uma unidade psiquiátrica em um hospital geral. 2008. 109 p. Dissertação (Mestrado em Ciências, área de Medicina Preventiva) - Universidade de São Paulo, São Paulo, 2008. Disponível em: http://www. 
teses.usp.br/teses/disponiveis/5/5137/tde-18062008-190535/publico/TeseLucchesiM.pdf . Acesso em: 01 jul. 2014.

MARTINHAGO, F. Desinstitucionalização e a prática nos Centros de Atenção Psicossocial (CAPS). 2011. 112 p. Dissertação (Mestrado em Saúde Coletiva) - Universidade Federal de Santa Catarina, Florianópolis, 2011. Disponível em: http://repositorio.ufsc.br/xmlui/ handle/123456789/95717. Acesso em: 01 jul. 2014.

MIRANDA, L. Transitando entre o coletivo e o individual: reflexóes sobre o trabalho de referência junto a pacientes psicóticos. 2009. 301 p. Tese (Doutorado em Saúde Coletiva) Universidade Estadual de Campinas, Campinas, 2009. Disponível em: http://www.fcm. unicamp.br/fcm/sites/default/files/tese_lilian_miranda.pdf. Acesso em: 28 jul. 2014.

MUNIZ, P.L. O fenômeno revolving door: um desafio à reforma psiquiátrica. 2013. 95 p. Dissertação (Mestrado em Saúde Coletiva). Universidade Federal Fluminense, Niterói, 2013. Disponível em: http://pesquisa.bvsalud.org/portal/resource/pt/lil-689415. Acesso em: 22 jul. 2014.

NASI, C. As expectativas dos usuários e as intenções dos trabalhadores de um Centro de Atenção Psicossocial. 2011. 168 p. Tese (Doutorado em Enfermagem) - Universidade Federal do Rio Grande do Sul, Porto Alegre, 2011. Disponível em: http://www.bibliotecadigital.ufrgs.br/ da.php?nrb=000782179\&loc=2011\&l=8f9b5debbe0527f2. Acesso em: 01 jul. 2014 .

OCTAVIANO, A.R. de C. Configuração de rede de assistência em saúde mental em município de pequeno porte: o caso de Pirai Rio de Janeiro. 2012. 116 p. Dissertação (Mestrado em Saúde Coletiva) - Instituto de Medicina Social, Universidade do Estado do Rio de Janeiro. Disponível em: http://www.tesesims.uerj.br/lildbi/docsonline/get.php?id=901. Acesso em: 01 jul. 2014.

OLIVEIRA, E de. O desafio de assistir pacientes com transtornos decorrentes de uso prejudicial e ou dependência de álcool e outras drogas. 2005. 186 p. Dissertação (Mestrado em Enfermagem Psiquiátrica) - Universidade de São Paulo, São Paulo, 2005. Disponível em: http://www. teses.usp.br/teses/disponiveis/7/7134/tde-07122006-152446. Acesso em: 01 jul. 2014.

OSINNAGA, V.L.M. Estudo comparativo entre os conceitos de saúde e de doença mental e a assistência psiquiátrica, segundo portadores e familiares. 2004. 142 p. Tese (Doutorado em Enfermagem Psiquiátrica) - Escola de Enfermagem de Ribeirão Preto, Universidade de São Paulo, Ribeirão Preto, 2004. Disponível em: http://www.teses.usp.br/teses/disponiveis/22/22131/tde27102004-152642/publico/doutorado.pdf. Acesso em: 01 jul. 2014.

PACHECO, R.P. Os itinerários terapêuticos de usuários de Centros de Atenção Psicossocial para crianças e adolescentes (CAPS-i) do município de São Paulo. 2009.173p. Dissertação (Mestrado em Saúde Pública) - Faculdade de Saúde Pública, Universidade de São Paulo, São Paulo, 2009. Disponível em: http://pesquisa.bvsalud.org/portal/resource/pt/lil-558096 . Acesso em: 01 jul. 2014. 
PEREIRA, M. de O. Um olhar sobre a atenção psicossocial a partir do itinerário terapêutico de adolescentes em crise. 2013. 198 p. Dissertação (Mestrado em Saúde Pública) - Escola Nacional de Saúde Pública Sergio Arouca, Fundação Oswaldo Cruz, Rio de Janeiro, 2013. Disponível em: http://bvssp.icict.fiocruz.br/lildbi/docsonline/get.php?id=3729. Acesso em: 01 jul. 2014

PINHEIRO, S.M. de A. O cuidado prestado pelo enfermeiro nos Centros de Referência em Saúde Mental de Belo Horizonte. 2011. 135 p. Dissertação (Mestrado em Enfermagem) - Universidade Federal de Minas Gerais, Belo Horizonte, 2011. Disponível em: http:// pesquisa.bvsalud.org/portal/resource/pt/lil-689290. Acesso em: 01 jul. 2014

PINTO, T.R. Encontros e desencontros: a Estratégia de Saúde da Família em sua relação com a rede de serviços e dispositivos substitutivos em saúde mental. 2007. 129 p. Dissertação (Mestrado em Saúde Coletiva, área de concentração de Saúde Pública) - Faculdade de Medicina de Botucatu, Universidade Estadual Paulista. Disponível em: http://pesquisa. bvsalud.org/portal/resource/pt/lil-493905. Acesso em: 16 jul. 2014.

PONTE, M.A.V. Internamento por crack: perfil dos usuários e padrão de assistência em hospital geral. 2012. 114 p. Dissertação (Mestrado em Saúde Pública, área de concentração de Epidemiologia) - Faculdade de Medicina, Universidade Federal do Ceará, Fortaleza, 2012. Disponível em: http://www.repositorio.ufc.br/handle/riufc/4021. Acesso em: 28 jul. 2014. PORTO, K.F. Elementos para uma politica de avaliação das ações de saúde mental na atenção primária: contribuições de uma pesquisa qualitativa avaliativa. 2012. 257 p. Dissertação (Mestrado em Saúde Coletiva) - Universidade Estadual de Campinas, Campinas, 2012. Disponível em: http:/www.fcm.unicamp.br/fcm/sites/default/files/dissertacao-karime_ porto_0.pdf.Acesso em: 01 jul. 2014.

PRESOTTO, R.F. Participação de usuários de serviços de saúde mental em pesquisas: um olhar a partir dos conceitos de empowerment e recovery. 2013. 151 p. Dissertação (Mestrado em Saúde Coletiva) - Universidade Estadual de Campinas, Campinas, 2013. Disponível em: http:// www.bibliotecadigital.unicamp.br/document/?code=000903077. Acesso em: 01 jul. 2014.

QUEBRA, S.C.F. Discurso moderno e psiquiatria reformada: consideraçôes sobre um Centro de Atenção Psicossocial. 2011. 151 p. Dissertação (Mestrado em Psicologia) - Universidade Federal do Pará, Belém, 2011. Disponível em: http://www.ppgp.ufpa.br/dissert/Samea_ Quebra.pdf. Acesso em: 01 jul. 2014.

RAINONE, F.N. Experiência e transmissão: o projeto Insere como articulador de reabilitação psicossocial no campo da saúde mental. 2012. 236 p. Tese (Doutorado em Educação) Universidade Federal do Rio Grande do Sul, Porto Alegre, 2012. Disponível em: http://hdl. handle.net/10183/69940. Acesso em: 01 jul. 2014.

RAMMINGER, T. Cada Caps é um Caps: a importância dos saberes investidos na atividade para o desenvolvimento do trabalho em saúde mental. 2009. 226p. Tese (Doutorado em 
Saúde Pública) - Escola Nacional de Saúde Pública Sérgio Arouca, Fundação Oswaldo Cruz, Rio de Janeiro, 2009. Disponível em: http://arca.icict.fiocruz.br/handle/icict/2551. Acesso em: 01 jul. 2014.

RAMOS, D.K.R. Reinternaçôes psiquiátricas no Rio Grande do Norte: implicaçôes e impacto das novas estratégias de atenção à saúde mental. 2011. 148 p. Mestrado (Dissertação em Enfermagem) - Universidade Federal do Rio Grande do Norte, Natal, 2011. Disponível em: http://repositorio.ufrn.br:8080/jspui/handle/1/9216. Acesso em: 01 jul. 2014.

RANGEL, M. N. A nova cronicidade nos novos serviços de atenção psicossocial. 2008. 146p. Dissertação (Mestrado em Ciências, área de Saúde Pública) - Escola Nacional de Saúde Pública Sérgio Arouca, Fundação Oswaldo Cruz, Rio de Janeiro, 2008. Disponível em: http://bvssp.icict.fiocruz.br/lildbi/docsonline/get.php?id=1485. Acesso em: 01 jul. 2014.

REINALDO, A.M. dos S. Gerenciamento de casos como estratégia de trabalho para enfermagem psiquiátrica comunitária. 2005. 233 p. Tese (Doutorado em Enfermagem Psiquiátrica) - Escola de Enfermagem de Ribeirão Preto, Universidade de São Paulo, Ribeirão Preto, 2005. Disponível em: http://www.teses.usp.br/teses/disponiveis/22/22131/tde-12082005095949/publico/REINALDO_AMS.pdf. Acesso em: 16 jul. 2014.

REIS, A.O. A. Os Centros de Atenção Psicossocial Infantojuvenis no estado de São Paulo. 2010. 236p. Tese (Livre-docência) - Departamento de Saúde Materno-Infantil, Faculdade de Saúde Pública, Universidade de São Paulo, São Paulo, 2010. Disponível em: http://pesquisa. bvsalud.org/portal/resource/pt/lil-594075. Acesso em: 01 jul. 2014.

RODRIGUES, D.R. Desenho e implantação de um sistema de informação para o serviço de saúde mental do município de Guapimirim. 2013. 70 p. Dissertação (Mestrado Profissional em Saúde Pública) - Escola Nacional de Saúde Pública Sergio Arouca, Fundação Oswaldo Cruz, Rio de Janeiro, 2013. Disponível em: http://bvssp.icict.fiocruz.br/lildbi/docsonline/ get.php?id=3685. Acesso em: 01 jul. 2014.

ROSA, R.P.F da. Espaço e loucura: uma análise dos espaços de cuidado na Reforma Psiquiátrica. 2011. 120 p. Dissertação (Mestrado em Psicologia) - Universidade Federal Fluminense, Niterói, 2011. Disponível em: http://capesdw.capes.gov.br/?login-url-success=/capesdw/\#. Acesso em: 01 jul. 2014.

SALLES, M.M. Internação em hospital psiquiátrico: o (des) caminho para vivência do cotidiano $e$ da inserção social. 2005. 233 p. Dissertação (Mestrado em Enfermagem) - Universidade de São Paulo, São Paulo, 2005. Disponível em: http://pesquisa.bvsalud.org/portal/resource/ pt/bde-16562. Acesso em: 01 jul. 2014.

SCHMIDT, M.B. Avaliação da qualidade de serviços de saúde mental: um estudo de caso do CAPS Profeta Gentileza. 2007. 450 p. Tese (Doutorado em Saúde Coletiva) - Instituto de Medicina Social, Universidade do Estado do Rio de Janeiro, Rio de Janeiro, 2007. Disponível em: http://pesquisa.bvsalud.org/portal/resource/pt/lil-476552. Acesso em: 16 jul. 2014. 
SILVEIRA, B.V. da. Admissão e envolvimento terapêutico em saúde mental: mão ou contramão de um mesmo processo? 2013.87 p. Dissertação (Mestrado em Enfermagem) - Universidade Federal de Minas Gerais, Belo Horizonte, 2013. Disponível em: http://hdl.handle.net/1843/ GCPA-97WHUB. Acesso em: 16 jul. 2014.

SILVEIRA, M.R. A saúde mental na Atenção Básica: um diálogo necessário. 2009. 145 p. Tese (Doutorado em Enfermagem) - Universidade Federal de Minas Gerais, Belo Horizonte, 2009. Disponível em: http://pesquisa.bvsalud.org/portal/resource/pt/lil-689326. Acesso em: 16 jul. 2014.

SOARES, S.R. R. Centro de Atenção Psicossocial: como o usuário vivencia o cotidiano do serviço. 2005. 146 p. Tese (Doutorado em Enfermagem Psiquiátrica) - Escola de Enfermagem de Ribeirão Preto, Universidade de São Paulo, São Paulo, 2005. Disponível em: http://www. teses.usp.br/teses/disponiveis/22/22131/tde-16042007-171040/. Acesso em: 16 jul. 2014.

SOUZA, A.C. de. Estratégias de inclusão da saúde mental na Atenção Básica no Rio de Janeiro: um movimento das marés. 2012. 156 p. Tese (Doutorado em Saúde Pública) - Escola Nacional de Saúde Pública Sérgio Arouca, Fundação Oswaldo Cruz, Rio de Janeiro, 2012. Disponível em: http://bvssp.icict.fiocruz.br/lildbi/docsonline/get.php?id=2906 . Acesso em: 16 jul. 2014.

SOUZA, V.S. Dispositivos existenciais de cuidado em saúde mental: percepção de pessoas em sofrimento psíquico. 2011. 145 p. Dissertação (Mestrado em Enfermagem, área de concentração de Saúde Pública) - Universidade Estadual do Sudoeste da Bahia, Jequié, 2011. Disponível em: http://www.uesb.br/ppgenfsaude/dissertacoes/turma2/DISSERTACAO-VIVIANEDOS-SANTOS-SOUZA.pdf. Acesso em: 01 jul. 2014.

SURJUS, L.T. de L. e S. Narrativas politicas: o olhar dos usuários sobre os Caps. 2007. 133 p. Dissertação (Mestrado em Saúde Coletiva) - Universidade Estadual de Campinas, Campinas, 2007. Disponível em: http:/www.fcm.unicamp.br/fcm/sites/default/files/ dissertacao_lucianatogni_0.pdf. Acesso em: 28 jul. 2014.

TEIXEIRA JUNIOR, S. Trajetórias assistenciais de usuários com transtornos psíquicos na rede de saúde do município de Porto Alegre. 2010. 138 p. Dissertação (Mestrado em Enfermagem) - Universidade Federal do Rio Grande do Sul, Porto Alegre, 2010. Disponível em: http:// www.bibliotecadigital.ufrgs.br/da.php? $\mathrm{nrb}=000768950 \& \mathrm{loc}=2011 \& \mathrm{l}=1 \mathrm{db}$ 9a9eed71ea 9b2. Acesso em: 01 jul. 2014.

TEIXEIRA, J.A. Avaliação da implantação da politica de atenção integral a usuários de álcool e outras drogas: um estudo de caso. 2011. 147 p. Dissertação (Mestrado em Enfermagem) Universidade Estadual de Maringá, Maringá, 2011. Disponível em: http://nou-rau.uem.br/ nou-rau/document/?code=vtls000194597. Acesso em: 16 jul. 2014.

TRAPÉ, T.L. O agente comunitário de saúde e a saúde mental: faces e interfaces. 2011. 160 p. Dissertação (Mestrado em Saúde Coletiva) - Universidade Estadual de Campinas, 
Campinas, 2011. Disponível em: http://www.fcm.unicamp.br/fcm/sites/default/files/ dissertacao_trapethiago_0.pdf. Acesso em: 28 jul. 2014.

VASCONCELOS, M.A. Projeto terapêutico como dispositivo de cuidado na rede de atenção à saúde mental e sua (des)articulação com a Estratégia Saúde da Família (ESF). 2011. 116 p. Dissertação (Mestrado em Saúde Pública) - Universidade Federal do Ceará, Fortaleza, 2011. Disponível em: http://www.uece.br/cmasp/dmdocuments/Dissertacao_Mardenia_ Gomes_Ferreira_Vasconcelos.pdf. Acesso em: 01 jul. 2014.

VELOSO, T.M. C. Açôes de saúde mental desenvolvidas no cotidiano de uma equipe de Estratégia Saúde da Familia: possibilidades e limites. 2012. 129 p. Dissertação (Mestrado em Enfermagem Psiquiátrica) - Escola de Enfermagem de Ribeirão Preto, Universidade de São Paulo, Ribeirão Preto, 2012. Disponível em: http://www.teses.usp.br/teses/ disponiveis/22/22131/tde-15082012-134531/pt-br.php. Acesso em: 01 jul. 2014.

\section{Artigos científicos}

ALVES, H.M. de C.; DOURADO, L.B.R.; CÔRTES, V. da N.Q. A influência dos vínculos organizacionais na consolidação dos Centros de Atenção Psicossociais. Ciênc. saúde colet., Rio de Janeiro, v. 18, n. 10, p. 2.965-2.975, out. 2013.

ALVES, T.C.; OLIVEIRA, W.F. de; VASCONCELOS, E.M. A visão de usuários, familiares e profissionais acerca do empoderamento em saúde mental. Physis, Rio de Janeiro, v. 23, n. 1, p. 51-71, 2013.

AMARANTE, A.L. et al. As estratégias dos enfermeiros para o cuidado em saúde mental no programa saúde da família. Texto contexto-enferm., Florianópolis, v. 20, n. 1, p. 85-93, mar. 2011.

AMORIM, A.K. de M.A.; DIMENSTEIN, M. Desinstitucionalização em saúde mental e práticas de cuidado no contexto do serviço residencial terapêutico. Ciênc. saúde colet., Rio de Janeiro, v. 14, n. 1, p. 195-204, fev. 2009.

ANTUNES, S.M.M. de O.; QUEIROZ, M. de S. A configuração da reforma psiquiátrica em contexto local no Brasil: uma análise qualitativa. Cad. Saúde Pública, Rio de Janeiro, v. 23, n. 1, p. 207-215, jan. 2007.

ARAUJO, A.K. de; TANAKA, O.Y. Avaliação do processo de acolhimento em Saúde Mental na região centro-oeste do município de São Paulo: a relação entre CAPS e UBS em análise. Interface, Botucatu, v. 16, n. 43, p. 917-928, dez. 2012.

ARGILES, C.T.L. et al. Redes de sociabilidade: construções a partir do serviço residencial terapêutico. Ciênc. saúde colet., Rio de Janeiro, v. 18, n. 7, p. 2.049-2.058, jul. 2013.

ATHAYDE, V.; HENNINGTON, E.A. A saúde mental dos profissionais de um Centro de Atenção Psicossocial. Physis, Rio de Janeiro, v. 22, n. 3, p. 983-1001, 2012. 
BANDEIRA, M. et al. Satisfação de familiares de pacientes psiquiátricos com os serviços de saúde mental e seus fatores associados. J. bras. psiquiatr., Rio de Janeiro, v. 60, n. 4, p. 284-293, 2011.

BARROS, M.M.M. de; CHAGAS, M.I.O.; DIAS, M.S. de A. Saberes e práticas do agente comunitário de saúde no universo do transtorno mental. Ciênc. saúde colet., Rio de Janeiro, v. 14, n. 1, p. 227-232, fev. 2009.

BARROS, M.M.M. de; JORGE, M.S.B.; VASCONCELOS, M.G.F. Experiências de famílias com usuários atendidos em dispositivos de atenção psicossocial. Physis, Rio de Janeiro, v. 23, n. 3, p. 821-841, set. 2013.

BIELEMANN, V. de L.M. et al. A inserção da família nos centros de atenção psicossocial sob a ótica de seus atores sociais. Texto contexto-enferm., Florianópolis, v. 18, n. 1, p. 131139, mar. 2009.

CALGARO, A.; SOUZA, E.N. de. Percepção do enfermeiro acerca da prática assistencial nos serviços públicos extra-hospitalares de saúde mental. Revista Gaúcha de Enfermagem, Porto Alegre, v. 30, n. 3, p. 476-483, 2009.

CAMATTA, M.W. et al. Avaliação de um Centro de Atenção Psicossocial: o olhar da família. Ciênc. saúde colet., Rio de Janeiro, v. 16, n. 11, p. 4.405-4.414, 2011.

CAMATTA, M.W.; SCHNEIDER, J.F. A visão da família sobre o trabalho de profissionais de saúde mental de um Centro de Atenção Psicossocial. Esc. Anna Nery, Rio de Janeiro, v. 13, n. 3, p. 477-484, 2009.

CAMPOS, R.O.; BACCARI, I.P. A intersubjetividade no cuidado à Saúde Mental: narrativas de técnicos e auxiliares de enfermagem de um Centro de Atenção Psicossocial. Ciênc. saúde colet., Rio de Janeiro, v. 16, n. 4, p. 2051-2058, abr. 2011 b.

CAMPOS, R.O. et al. Saúde mental na atenção primária à saúde: estudo avaliativo em uma grande cidade brasileira. Ciênc. saúde colet., Rio de Janeiro, v. 16, n. 12, p. 4.6434.652, dez. 2011a.

CAMPOS, R.T.O. et al. Avaliação da rede de Centros de Atenção Psicossocial: entre a saúde coletiva e a saúde mental. Rev. Saúde Públ., São Paulo, v. 43, supl.1, p. 16-22, ago. 2009.

CARVAlHO, M.D.A.; SILVA, H.O.; RODRIGUES, L.V. Perfil epidemiológico dos usuários da rede de saúde mental do município de Iguatu, CE. SMAD, Rev. Eletrônica Saúde Mental Álcool Drog., Ribeirão Preto, v. 6, n. 2, p. 337-349, 2010.

CAVALCANTE, C.M.; JORGE, M.S.B.; SANTOS, D.C.M. dos. Onde está a criança? Desafios e obstáculos ao apoio matricial de crianças com problemas de saúde mental. Physis, Rio de Janeiro, v. 22, n. 1, p. 161-178, 2012.

CONSOLI, G.L.; HIRDES, A.; COSTA, J.S. D. da. Saúde mental nos municípios do Alto Uruguai, RS, Brasil: um diagnóstico da reforma psiquiátrica. Ciênc. saúde colet., Rio de Janeiro, v. 14, n. 1, p. 117-128, fev. 2009. 
COSTA, C.S. et al. A percepção de pacientes e familiares sobre os resultados do tratamento em serviços de saúde mental. Cad. Saúde Pública, Rio de Janeiro, v. 27, n. 5, p. 995-1007, maio 2011.

COUTO, M.C.V.; DUARTE, C.S.; DELGADO, P.G.G. A saúde mental infantil na Saúde Pública brasileira: situação atual e desafios. Rev. Bras. Psiquiatr., Rio de Janeiro, v. 30, n. 4, p. 384-389, dez. 2008.

DE MARCO, P.F. et al. O impacto do trabalho em saúde mental: transtornos psiquiátricos menores, qualidade de vida e satisfação profissional. J. bras. psiquiatr, Rio de Janeiro, v. 57, n. 3, p. 178-183, 2008.

DELFINI, P.S. de S.; REIS, A.O. A. Articulação entre serviços públicos de saúde nos cuidados voltados à saúde mental infanto-juvenil. Cad. Saúde Pública, Rio de Janeiro, v. 28, n. 2, p. 357-366, fev. 2012.

FIGUEIREDO, M.D.; CAMPOS, R. Saúde Mental na atenção básica à saúde de Campinas, SP: uma rede ou um emaranhado? Ciênc. saúde colet., Rio de Janeiro, v. 14, n. 1, p. 129-138, fev. 2009.

FIORATI, R.C.; SAEKI, T. Predominância da tecnologia médico-clínica sobre ações de atenção psicossocial em serviços extra-hospitalares de saúde mental. Ciênc. saúde colet., Rio de Janeiro, v. 18, n. 10, p. 2.957-2.963, out. 2013.

FURTADO, J.P. Avaliação da situação atual dos Serviços Residenciais Terapêuticos no SUS. Ciênc. saúde colet., Rio de Janeiro, v. 11, n. 3, p. 785-795, set. 2006.

FURTADO, J.P. et al. A elaboração participativa de indicadores para a avaliação em saúde mental. Cad. Saúde Pública, Rio de Janeiro, v. 29, n. 1, p. 102-110, jan. 2013.

GALVANESE, A.T.C.; NASCIMENTO, A.F.; D’OLIVEIRA, A.F.P.L. Arte, cultura e cuidado nos centros de atenção psicossocial. Rev. Saúde Públ., São Paulo, v. 47, n. 2, p. 3607, abr. 2013.

GARCIA, M.L.P.; JORGE, M.S.B. Vivência de trabalhadores de um centro de atenção psicossocial: estudo à luz do pensamento de Martin Heidegger e Hans-Georg Gadamer. Ciênc. saúde colet., Rio de Janeiro, v. 11, n. 3, p. 178-183, set. 2006.

GASTAL, C.L.C.; GUTFREIND, C. Um estudo comparativo de dois serviços de saúde mental: relaçôes entre participação popular e representaçôes sociais relacionadas ao direito à saúde. Cad. Saúde Pública, Rio de Janeiro, v. 23, n. 8, p. 1.835-1.844, ago. 2007.

GUIMARĀES, J.M.X.; JORGE, M.S.B.; ASSIS, M.M.A. (In)satisfação com o trabalho em saúde mental: um estudo em Centros de Atenção Psicossocial. Ciênc. saúde colet., Rio de Janeiro, v. 16, n. 4, p. 2.145-2.154, abr. 2011.

HECK, R.M. et al. Gestão e saúde mental: percepçōes a partir de um Centro de Atenção Psicossocial. Texto contexto-enferm., Florianópolis, v. 17, n. 4, p. 647-655, dez. 2008. 
HECKERT, U.; TEIXEIRA, L.S.; TRINDADE, A. de S. Avaliação da satisfação dos usuários do Centro Regional de Referência em Saúde Mental (CRRESAM) da região central de Juiz de Fora, MG. HU Rev, Juiz de Fora, v. 32, n. 1, p. 15-19, 2006.

HOFFMANN, M.C.C.L.; SANTOS, D.N.; MOTA, E.L.A. Caracterização dos usuários e dos serviços prestados por Centros de Atenção Psicossocial Infanto-Juvenil. Cad. Saúde Pública, Rio de Janeiro, v. 24, n. 3, p. 633-642, mar. 2008.

JAEGGER, R.C. et al. A experiência de morar fora: avaliação da satisfação de usuários em um serviço de saúde mental. Cad. Saúde Colet., Rio de Janeiro, v. 12, n. 1, p. 27-39, 2004.

JORGE, M.S.B. et al. Experiências com a gestão autônoma da medicação: narrativa de usuários de saúde mental no encontro dos grupos focais em centros de atenção psicossocial. Physis, Rio de Janeiro, v. 22, n. 4, p. 1.543-1.561, 2012.

JORGE, M.S.B. et al. Promoção da Saúde Mental - Tecnologias do Cuidado: vínculo, acolhimento, co-responsabilização e autonomia. Ciênc. saúde colet., Rio de Janeiro, v. 16, n. 7, p. 3.051-3.060, 2011.

JUCÁ, V.J. dos S.; NUNES, M. de O.; BARRETO, S.G. Programa de Saúde da Família e Saúde Mental: impasses e desafios na construção da rede. Ciênc. saúde colet., Rio de Janeiro, v. 14, n. 1, p. 173-182, fev. 2009.

KANTORSKI, L.P. et al. Contribuições do Estudo de Avaliação dos Centros de Atenção Psicossocial da Região Sul do Brasil. Cad. Bras. Saúde Mental, Florianópolis, v. 1, n. 1, p. 202-211, 2009.

KILSZTAJN, S. et al. Leitos hospitalares e reforma psiquiátrica. Cad. Saúde Pública, Rio de Janeiro, v. 24, n. 10, p. 2.354-2.362, 2008.

KODA, M.Y.; FERNANDES, M.I.A. A reforma psiquiátrica e a constituição de práticas substitutivas em saúde mental: uma leitura institucional sobre a experiência de um núcleo de atenção psicossocial. Cad. Saúde Pública, Rio de Janeiro, v. 23, n. 6, p. 1.455-1.461, jun. 2007. LIMA, M. et al. Signos, significados e práticas de manejo da crise em Centros de Atenção Psicossocial. Interface, Botucatu, v. 16, n. 41, p. 423-434, jun. 2012.

LOCH, A.A. Stigma and higher rates of psychiatric re-hospitalization: São Paulo public mental health system. Rev. Bras. Psiquiatr., São Paulo, v. 34, n.2, p. 185-192, 2012.

LUZIO, C.A.; L'ABBATE, S. A atenção em Saúde Mental em municípios de pequeno e médio portes: ressonâncias da reforma psiquiátrica. Ciênc. saúde colet., Rio de Janeiro, v. 14, n. 1, p. 105-116, fev. 2009.

MACHADO, V.; MANÇO, A.R.X.; SANTOS, M.A.D dos. A recusa à desospitalização psiquiátrica: um estudo qualitativo. Cad. Saúde Pública, Rio de Janeiro, v. 21, n. 5, p. $1472-$ 1479, out. 2005 . 
MACHADO, V.; SANTOS, M.A. dos. O tratamento extra-hospitalar em saúde mental na perspectiva do paciente reinternado. Psicol. estud., Maringá, v. 18, n. 4, p. 701-712, dez. 2013. MATEUS, M.D. et al. The mental health system in Brazil: Policies and future challenges. Int. J. Ment. Health Syst., London, v. 2, n. 1, p. 12-19, jan. 2008.

MÁXIMO, H. dos R.M.; BOSI, M.L.M. Saúde mental em um hospital público: o olhar de profissionais médicos do município do Rio de Janeiro. Physis, Rio de Janeiro, v. 16, n. 2, p. 293-316, 2006.

MELO, A.P.S.; GUIMARÃES, M.D.C. Factors associated with psychiatric treatment dropout in a mental health reference center, Belo Horizonte. Rev. Bras. Psiquiatr., São Paulo, v. 27, n. 2, p. 113-118, jun. 2005.

MIELKE, F.B. et al. O cuidado em saúde mental no CAPS no entendimento dos profissionais. Ciênc. saúde colet., Rio de Janeiro, v. 14, n. 1, p. 159-164, fev. 2009.

MIELKE, F.B. et al. Avaliação de um serviço substitutivo em saúde mental. Cogitare enferm., Curitiba, v. 14, n. 1, p. 52-8, 2009.

MIELKE, F.B.; OLCHOWSKY, A. Saúde mental na Estratégia Saúde da Família: a avaliação de apoio matricial. Rev Bras Enferm, Brasília, v. 63, n. 6, p. 900-907, dez. 2010.

MIELKE, F.B. et al. Avaliação qualitativa da relação de atores sociais com a loucura em um serviço substitutivo de saúde mental. Rev Bras Enferm, Brasília, v. 65, n. 3, p. 501-507, jun. 2012.

MIRANDA, L.; ONOCKO-CAMPOS, R.T. Análise das equipes de referência em saúde mental: uma perspectiva de gestão da clínica. Cad. Saúde Pública, Rio de Janeiro, v. 26, n. 6, p. 1.153-1.162, jun. 2010.

NARDI, H.C.; RAMMINGER, T. Modos de subjetivação dos trabalhadores de saúde mental em tempos de Reforma Psiquiátrica. Physis, Rio de Janeiro, v. 17, n. 2, p. 265-287, 2007.

NASCIMENTO, A. de F.; GALVANESE, A.T.C. Avaliação da estrutura dos Centros de Atenção Psicossocial do município de São Paulo, SP. Rev. Saúde Públ., São Paulo, v. 43, ago. 2009.

NASI, C.; SCHNEIDER, J.F. O Centro de Atenção Psicossocial no cotidiano dos seus usuários. Rev Esc Enferm USP, São Paulo, v. 45, n. 5, p. 1.157-1.163, out. 2011.

NUNES, M.; JUCÁ, V.J.; VALENTIM, C.P.B. Ações de saúde mental no Programa Saúde da Família: confluências e dissonâncias das práticas com os princípios das reformas psiquiátrica e sanitária. Cad. Saúde Pública, Rio de Janeiro, v. 23, n. 10, p. 2.375-2.384, out. 2007.

NUNES, M. et al. A dinâmica do cuidado em saúde mental: signos, significados e práticas de profissionais em um Centro de Assistência Psicossocial em Salvador, Bahia, Brasil. Cad. Saúde Pública, Rio de Janeiro, v. 24, n. 1, p. 188-196, jan. 2008. 
OLIVEIRA, J.A.; PASSOS, E. Efeitos transversais da supervisão clínico-institucional na rede de atenção psicossocial. Polis e Psique, Porto Alegre, v. 2, p. 171-187, 2012.

OLSCHOWSKY, A. et al. Avaliação de um Centro de Atenção Psicossocial: a realidade em Foz do Iguaçu. Rev Esc Enferm USP, São Paulo, v. 43, n. 4, p. 781-787, dez. 2009.

ONOCKO-CAMPOS, R.T. et al. A Gestão Autônoma da Medicação: uma intervenção analisadora de serviços em saúde mental. Ciênc. saúde colet., Rio de Janeiro, v. 18, n. 10, p. 2.889-2.898, out. 2013.

ONOCKO-CAMPOS, R.T. et al. Avaliação de estratégias inovadoras na organização da Atenção Primária à Saúde. Rev. Saúde Públ., São Paulo, v. 46, n. 1, p. 43-50, fev. 2012.

PANDE, M.N.R.; AMARANTE, P.D. de C. Desafios para os Centros de Atenção Psicossocial como serviços substitutivos: a nova cronicidade em questão. Ciênc. saúde colet., Rio de Janeiro, v. 16, n. 4, p. 2.067-2.076, abr. 2011.

PARANHOS-PASSOS, F.; AIRES, S. Reinserção social de portadores de sofrimento psíquico: o olhar de usuários de um Centro de Atenção Psicossocial. Physis, Rio de Janeiro v. 23, n. 1, p. 13-31, 2013.

PASSOS, E. et al. O Comitê Cidadão como estratégia cogestiva em uma pesquisa participativa no campo da saúde mental. Ciênc. saúde colet., Rio de Janeiro, v. 18, n. 10, p. 2.919-2.928, out. 2013.

PELISOLI, C. da L.; MOREIRA, A.K. Caracterização epidemiológica dos usuários do Centro de Atenção Psicossocial Casa Aberta. Rev. psiquiatr. Rio Gd. Sul, Porto Alegre, v. 27, n. 3, p. 270-277, dez. 2005.

PEREIRA, P.K. et al. Transtornos mentais e comportamentais no Sistema de Informações Hospitalares do SUS (SIH-SUS) no estado do Rio de Janeiro no período de 1999 a 2010. Cad. Saúde Coletiva, Rio de Janeiro, v. 20, n. 4, p. 482-491, 2012.

PINHO, L.B. de; HERNÁNDEZ, A.M.B.; KANTORSKI, L.P. Serviços substitutivos de saúde mental e inclusão no território: contradições e potencialidades. Cienc. Cuid. Saude, Maringá, v. 9, n. 1, p. 28-35, jul. 2010.

PINHO, L.B. de et al. Atividades terapêuticas: compreensão de familiares e profissionais de um centro de atenção psicossocial. Esc Anna Nery, Rio de Janeiro, v. 17, n. 3, p. 534541, set. 2013.

PINHO, L.B. de et al. Avaliação qualitativa do processo de trabalho em um centro de atenção psicossocial no Brasil. Rev. Panam. Salud Públ., Washington DC, v. 30, n. 4, p. 354-360, 2011.

PINTO, A.G.A. et al. Apoio matricial como dispositivo do cuidado em saúde mental na atenção primária: olhares múltiplos e dispositivos para resolubilidade. Ciênc. saúde colet., Rio de Janeiro, v. 17, n. 3, p. 653-660, mar. 2012. 
QUEIROZ, M. de S.; DELAMUTA, L.A. Saúde mental e trabalho interdisciplinar: a experiência do "Cândido Ferreira" em Campinas. Ciênc. saúde colet., Rio de Janeiro, v. 16, n. 8, p. 3.603-3.612, ago. 2011.

QUINDERÉ, P.H.D. et al. Acessibilidade e resolubilidade da assistência em saúde mental: a experiência do apoio matricial. Ciênc. saúde colet., Rio de Janeiro, v. 18, n. 7, p. 2.1572.166, jul. 2013.

RIBEIRO, L.M. et al. Saúde mental e enfermagem na Estratégia Saúde da Família: como estão atuando os enfermeiros? Rev Esc Enferm USP, São Paulo, v. 44, n. 2, p. 376-382, jun. 2010.

RIBEIRO, M.S. et al. Fatores associados ao abandono de tratamento em saúde mental em uma unidade de nível secundário do Sistema Municipal de Saúde. J. bras. psiquiatr, Rio de Janeiro, v. 57, n. 1, p. 16-22, 2008.

RIBEIRO, M.S. et al. Comparação da assistência em saúde mental em unidades básicas de saúde com ou sem equipe do Programa de Saúde da Família. Rev. psiquiatr. Rio Gd. Sul, Porto Alegre, v. 31, n. 1, p. 40-50, 2009.

RONZANI, T.M. et al. Implantação de rotinas de rastreamento do uso de risco de álcool e de uma intervenção breve na atenção primária à saúde: dificuldades a serem superadas. Cad. Saúde Pública, Rio de Janeiro, v. 21, n. 3, p. 852-861, jun. 2005.

SANTOS, M.V.D. dos et al. Análise do trabalho da equipe de um Centro de Atenção Psicossocial na perspectiva dos usuários. Saúde e Transformação Social, Florianópolis, v. 1, n. 2, p. 94-100, 2011.

SCHMIDT, M.B.; FIGUEIREDO, A.C. Acesso, acolhimento e acompanhamento: três desafios para o cotidiano da clínica em saúde mental. Rev. latinoam. psicopatol. fundam., São Paulo, v. 12, n. 1, p. 130-140, 2009.

SCHNEIDER, J.F. et al. Atendimento a usuários de drogas na perspectiva dos profissionais da estratégia saúde da família. Texto contexto-enferm., Florianópolis, v. 22, n. 3, p. 654-661, set. 2013.

SCHNEIDER, J.F. et al. Concepções de uma Equipe de Saúde Mental Sobre Interdisciplinaridade. Revista Gaúcha de Enfermagem, Porto Alegre, v. 30, n. 3, p. 397405, 2009.

SEVERO, A.K. de S. et al. A experiência de familiares no cuidado em saúde mental. Arquivos Brasileiros de Psicologia, v. 59, n. 2, p. 143-155, 2007.

SILVA, M.A. da et al. Satisfação dos pacientes com os serviços de saúde mental: a percepção de mudanças como preditora. J. bras. psiquiatr, Rio de Janeiro, v. 61, n. 2, p. 64-71, 2012.

SILVA, M.B.B. Atenção psicossocial e gestão de populaçôes: sobre os discursos e as práticas em torno da responsabilidade no campo da saúde mental. Physis, Rio de Janeiro, v. 15, n. 1, p. 127-150, jun. 2005. 
SILVA, M.B.B. Reforma, responsabilidades e redes: sobre o cuidado em saúde mental.

Ciênc. saúde colet., Rio de Janeiro, v. 14, n. 1, p. 149-158, 2009.

SILVA, M.T. da; LANCMAN, S.; ALONSO, C.M. do C. Consequências da intangibilidade na gestão dos novos serviços de saúde mental. Rev. Saúde Públ., São Paulo, v. 43, supl. 1, p. 33-42, ago. 2009.

SILVEIRA, D.P. da; VIEIRA, A.L.S. Saúde mental e atenção básica em saúde: análise de uma experiência no nível local. Ciênc. saúde colet., Rio de Janeiro, v. 14, n. 1, p. 139-148, fev. 2009.

SOARES, S.R.R.; SAEKI, T. The Psychosocial Care Center on the users point of view. Rev. Latino-Am. Enfermagem, Ribeirão Preto, v. 14, n. 6, p. 923-929, dez. 2006.

SOUSA, F.S.P. de et al. Tecendo a rede assistencial em saúde mental com a ferramenta matricial. Physis, Rio de Janeiro, v. 21, n. 4, p. 1.579-1.599, dez. 2011.

SOUZA, A. de J.F. et al. A saúde mental no Programa de Saúde da Família. Rev Bras Enferm, Brasília, v. 60, n. 4, p. 391-395, ago. 2007.

SOUZA, J. de et al. Intervenções de saúde mental para dependentes de álcool e outras drogas: das políticas à prática cotidiana. Texto contexto- enferm., Florianópolis, v. 21, n. 4, p. 729-738, 2012.

SURJUS, L.T. de L. e S.; CAMPOS, R.O. A avaliação dos usuários sobre os Centros de Atenção Psicossocial (CAPS) de Campinas, SP. Rev. latinoam. psicopatol. fundam., São Paulo, v. 14, n. 1, p. 122-133, mar. 2011.

TANAKA, O.Y.; LAURIDSEN-RIBEIRO, E. Desafio para a atenção básica: incorporação da assistência em saúde mental. Cad. Saúde Pública, Rio de Janeiro, v. 22, n. 9, p. 1.845$1.853,2006$.

TANAKA, O.Y.; RIBEIRO, E.L. Ações de saúde mental na atenção básica: caminho para ampliação da integralidade da atenção. Ciênc. saúde colet., Rio de Janeiro, v. 14, n. 2, p. 477-486, abr. 2009.

TAVARES, C.M. de M.; SOBRAL, V.R.S. Avaliação das práticas de cuidar envolvendo arte no âmbito do Centro de Atenção Psicossocial (CAPS). REME - Revista Mineira de Enfermagem, Belo Horizonte, v. 9, n. 2, p. 121-125, 2005.

TOFOLI, L.F.; FORTES, S. Apoio Matricial de Saúde Mental no Município de Sobral, CE: o relato de uma experiência. SANARE, Sobral, v. 6, n. 2, p. 34-42, 2007.

VANNUCCHI, A.M.C.; CARNEIRO JUNIOR, N. Modelos tecnoassistenciais e atuação do psiquiatra no campo da atenção primária à saúde no contexto atual do Sistema Único de Saúde, Brasil. Physis, Rio de Janeiro, v. 22, n. 3, p. 963-982, 2012.

VASCONCELOS, M.G.F. et al. Saúde Mental no Contexto do Programa de Saúde da Família: Representações Sociais de Usuários e Familiares. Rev Rene, Fortaleza, v. 9, n. 3, p. 9-16, 2008. 
WETZEL, C. et al. Dimensões do objeto de trabalho em um Centro de Atenção Psicossocial. Ciênc. saúde colet., Rio de Janeiro, v. 16, n. 4, p. 2.133-2.143, abr. 2011.

ZAMBENEDETTI, G.; PERRONE, C.M. O Processo de construção de uma rede de atenção em Saúde Mental: desafios e potencialidades no processo de Reforma Psiquiátrica. Physis, Rio de Janeiro, v. 18, n. 2, p. 277-293, 2008.

\section{Notas}

${ }^{1}$ De forma geral, define-se a avaliação em saúde como um processo crítico-reflexivo, contínuo e sistemático sobre práticas e processos, que resulta em indicadores de natureza quantitativa e/ou qualitativa (DECS, s/d).

${ }^{2}$ Segundo Zulmira Hartz, "a meta-avaliação - avaliação da avaliação - pode ser conceituada operacionalmente como um processo de descrição e julgamento de um estudo ou qualquer procedimento de avaliação, fundamentada em padrōes e critérios propostos e validados pelas associações profissionais e outros organismos auditores. Ela consiste, portanto, na verificação da coerência teórica e prática da pesquisa com os padrōes internacionais e/ou governamentais do controle de qualidade das avaliaçôes de políticas públicas" (HARTZ, 2006). Sobre as diversas técnicas propostas para realizar sínteses de dados qualitativos, consultar a revisão de Barros et al. (2011).

${ }^{3}$ A Portaria no. 224/SNAS, de 29 de janeiro de 1992, estabelecia as normas de funcionamento dos Núcleos/Centros de Atenção Psicossocial (NAPS/CAPS) e os definia como equipamentos intermediários entre a atenção ambulatorial e a internação hospitalar.

${ }^{4}$ O recente Plano de ação sobre Saúde Mental (2013-2020) da Organização Mundial da Saúde (OMS, 2013), indica os princípios transversais para embasar as políticas nacionais de saúde mental, dos quais destacamos dois concernentes à presente discussão: que as estratégias, ações e intervenções terapêuticas, de prevenção e promoção à saúde estejam baseadas em evidências científicas e/ou em práticas de excelência; e que as pessoas com transtornos mentais e incapacidades psicossociais se emancipem e participem da promoção, políticas, planejamento, legislação, prestação de serviços, acompanhamento, pesquisa e avaliação em saúde mental.

${ }^{5}$ Sobre a questão das evidências científicas em saúde mental, observamos, como Delgado (2010, p. XIV), que no Brasil, "o debate sobre ser ou não o tratamento no sistema público 'baseado em evidências' desenrolou-se nos últimos anos sob a marca de um simplismo maniqueísta e inculto”, de maneira muito diferente, por exemplo, do que ocorre na Inglaterra, em que o serviço público nacional de saúde é o grande fomentador da produção de evidências, por meio de variados métodos (não somente quantitativos), sendo estas usadas criticamente para guiar a prática clínica e a organização de serviços.

${ }^{6}$ C.R. Dantas e A.M.G.R. Oda participaram igualmente da concepção e projeto, análise e interpretação dos dados; redação do artigo e revisão crítica relevante do conteúdo intelectual; e aprovação final da versão a ser publicada. 


\section{Abstract}

Mapping of inquiries in mental health care in Brazil (2004-2013)

This work aims to map the research on public mental health services evaluation carried out in Brazil in the last 10 years. We searched electronic databases for dissertations, theses and academic papers. We selected 68 dissertations and theses, and 103 articles. Most of dissertations and theses were produced by Public Health and Nursing graduate programs in the states of São Paulo and Rio de Janeiro. The articles refer to services located in a restricted number of municipalities in the South and Southeast regions of the country, mainly in Rio Grande do Sul and São Paulo, with few nationwide studies. Throughout the production, the Psychosocial Community Centers, followed by Primary Health Care, are the most frequently evaluated services. Mental health workers, followed by service-users were the main source of information in the studies. Most work uses qualitative methodology. We conclude that, taken as a whole, evaluative researches in Brazil have focused on a few approaches to the process of mental health care reform, and that they are not comprehensive enough to provide information on national mental health indicators.

Key words: Mental Health Services Evaluation; Empirical Research - Mental Health; Psychosocial Community Centers; Primary Health Care - Mental Health; Unified Health System Brazil. 